\title{
Catalysing sustainable fuel and chemical synthesis
}

\author{
Adam F. Lee
}

Received: 5 February 2014/ Accepted: 17 March 2014/Published online: 9 April 2014

(c) The Author(s) 2014. This article is published with open access at Springerlink.com

\begin{abstract}
Concerns over the economics of proven fossil fuel reserves, in concert with government and public acceptance of the anthropogenic origin of rising $\mathrm{CO}_{2}$ emissions and associated climate change from such combustible carbon, are driving academic and commercial research into new sustainable routes to fuel and chemicals. The quest for such sustainable resources to meet the demands of a rapidly rising global population represents one of this century's grand challenges. Here, we discuss catalytic solutions to the clean synthesis of biodiesel, the most readily implemented and low cost, alternative source of transportation fuels, and oxygenated organic molecules for the manufacture of fine and speciality chemicals to meet future societal demands.
\end{abstract}

Keywords Heterogeneous catalysis - Biofuels - Biodiesel · Selective oxidation · Alcohols

\section{Introduction}

Sustainability, in essence the development of methodologies to meet the needs of the present without compromising those of future generations has become a watchword for modern society, with developed and developing nations and multinational corporations promoting international research programmes into sustainable food, energy, materials and even city planning. In the context of energy and materials (specifically synthetic chemicals), despite significant growth in proven and predicted fossil fuel reserves over the next two

\footnotetext{
A. F. Lee $(\square)$

European Bioenergy Research Institute, Aston University, Aston Triangle, Birmingham B4 7ET, UK

e-mail: a.f.lee@warwick.ac.uk; a.f.lee@aston.ac.uk
}

decades, notably heavy crude oil, tar sands, deepwater wells, and shale oil and gas, there are great uncertainties in the economics of their exploitation via current extraction methodologies, and crucially, an increasing proportion of such carbon resources (estimates vary between 65 and $80 \%$ [1-3]) cannot be burned without breaching the UNFCC targets for a $2{ }^{\circ} \mathrm{C}$ increase in mean global temperature relative to the pre-industrial level $[4,5]$. There is clearly a tightrope to walk between meeting rising energy demands, predicted to rise $50 \%$ globally by 2040 [6] and the requirement to mitigate current $\mathrm{CO}_{2}$ emissions and hence climate change. The quest for sustainable resources to meet the demands of a rapidly rising global population represents one of this century's grand challenges [7, 8].

While many alternative sources of renewable energy have the potential to meet future energy demands for stationary power generation, biomass offers the most readily implemented, low cost solution to a drop-in transportation fuel for blending with/replacing conventional diesel [9] via carbohydrate hydrodeoxygenation (HDO) or lipid transesterification illustrated in Scheme 1. First generation biobased fuels derived from edible plant materials received much criticism over the attendant competition between land usage for fuel crops versus traditional agricultural cultivation [10]. Deforestation practices, notably in Indonesia, wherein vast tracts of rainforest and peat land are being cleared to support palm oil plantations have also provoked controversy [11]. To be considered sustainable, second generation bio-based fuels and chemicals are sought that use biomass sourced from non-edible components of crops, such as stems, leaves and husks or cellulose from agricultural or forestry waste. Alternative non-food crops such as switchgrass or Jatropha curcas [12], which require minimal cultivation and do not compete with traditional arable land or drive deforestation, are other potential candidate biofuel 


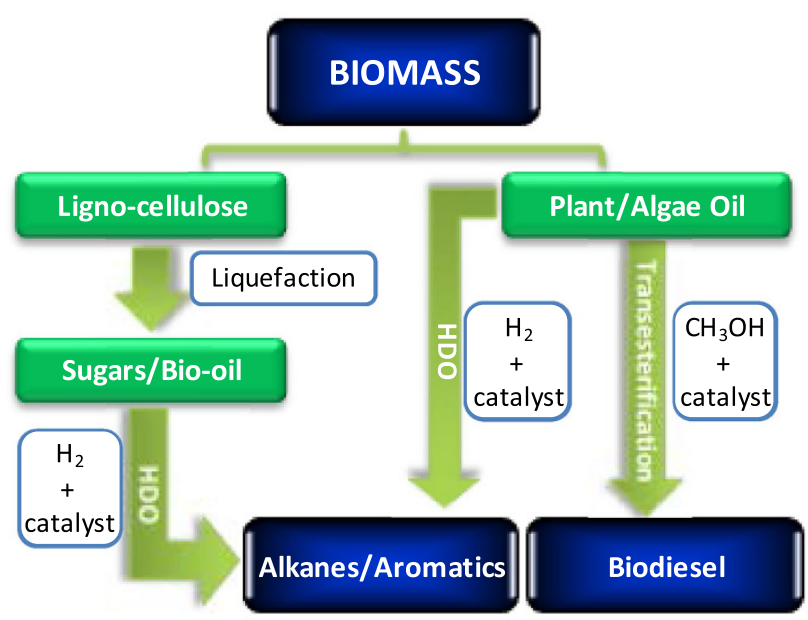

Scheme 1 Chemical conversion routes for the co-production of chemicals and transportation fuels from biomass

feedstocks. There is also growing interest in extracting biooils from aquatic biomass, which can yield 80-180 times the annual volume of oil per hectare than that obtained from plants [13]. Approximately $9 \%$ of transportation energy needs are predicted to be met via liquid bio-fuels by 2030 [14]. While the abundance of land and aquatic biomass, and particularly of agricultural, forestry and industrial waste, is driving the search for technologies to transform lignocellulose into fuels and chemical, energy and atom-efficient processes to isolate lignin and hemicellulose from the more tractable cellulose component, remain to be identified [15]. Thermal pyrolysis offers one avenue by which to obtain transportation fuels, and wherein catalysis will undoubtedly play a significant role in both pyrolysis of raw biomass and subsequent upgrading of bio-oils via deoxygenation and carbon chain growth. Catalytic depolymerisation of lignin may also unlock opportunities for the production of phenolics and related aromatic compounds for fine chemical and pharmaceutical applications [16].

Biodiesel is a clean burning and biodegradable fuel which, when derived from non-food plant or algal oils or animal fats, is viewed as a viable alternative (or additive) to current petroleum-derived diesel [17]. Commercial biodiesel is currently synthesised via liquid base-catalysed transesterification of $\mathrm{C}_{14}-\mathrm{C}_{20}$ triacylglyceride (TAG) components of lipids with $\mathrm{C}_{1}-\mathrm{C}_{2}$ alcohols [18-21] into fatty acid methyl esters (FAMEs) which constitute biodiesel as shown in Scheme 2, alongside glycerol as a potentially valuable by-product [22]. While the use of higher (e.g. $\mathrm{C}_{4}$ ) alcohols is also possible [23], and advantageous in respect of producing a less polar and corrosive FAME [24] with reduced cloud and pour points [25], the current high cost of longer chain alcohols, and difficulties associated with separating the heavier FAME product from unreacted alcohol and glycerol, remain problematic.

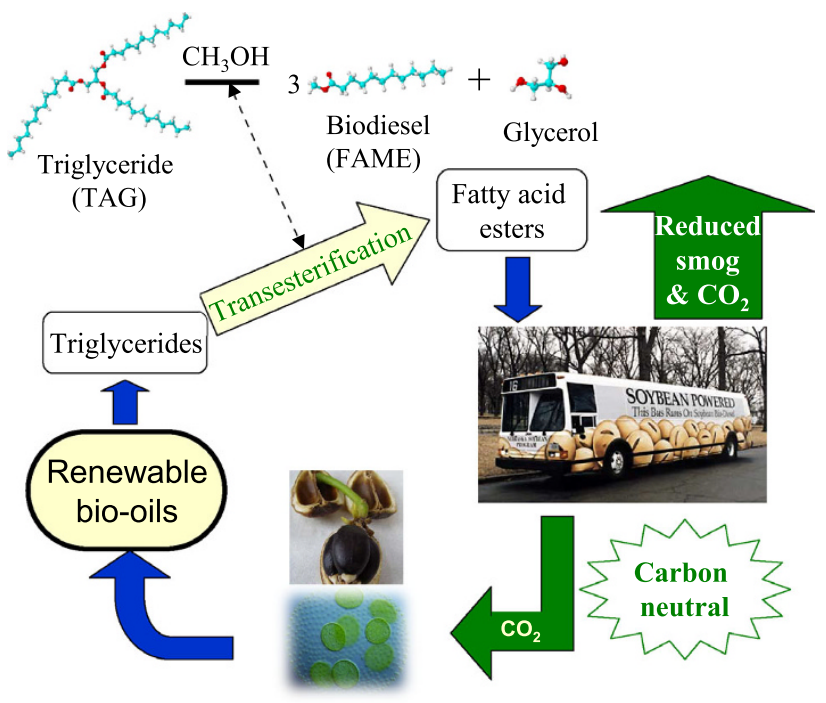

Scheme 2 Carbon cycle for biodiesel production from renewable bio-oils via catalytic transesterification

Unfortunately, homogeneous acid and base catalysts can corrode reactors and engine manifolds, and their removal from the resulting biofuel is particularly problematic and energy intensive, requiring aqueous quench and neutralisation steps which result in the formation of stable emulsions and soaps [9, 26, 27]. Such homogeneous approaches also yield the glycerine by-product, of significant potential value to the pharmaceutical and cosmetic industries, in a dilute aqueous phase contaminated by inorganic salts. Heterogeneous catalysis has a rich history of facilitating energy efficient selective molecular transformations and contributes to $90 \%$ of chemical manufacturing processes and to more than $20 \%$ of all industrial products [28, 29]. While catalysis has long played a pivotal role in petroleum refining and petrochemistry, in a post-petroleum era, it will face new challenges as an enabling technology to overcoming the engineering and scientific barriers to economically feasible routes to bio-fuels. The utility of solid base and acid catalysts for biodiesel production has been extensively reviewed [20,30-33], wherein they offer improved process efficiency by eliminating the need for quenching steps, allowing continuous operation [34], and enhancing the purity of the glycerol by-product. Technical advances in catalyst and reactor design remain essential to utilise non-food based feedstocks and thereby ensure that biodiesel remains a key player in the renewable energy sector for the 21 st century. Select pertinent developments in tailoring the nanostructure of solid acid and base catalysts for TAG transesterification to FAMEs and the related esterification of free fatty acid (FFAs) impurities common in bio-oil feedstocks are therefore discussed herein.

Biomass also offers the only non-fossil fuel route to organic molecules for the manufacture of bulk, fine and 
Scheme 3 Cartoon depicting the atom-efficient, chemoselective aerobic selective oxidation of allylic alcohols to aldehydes over a heterogeneous catalyst

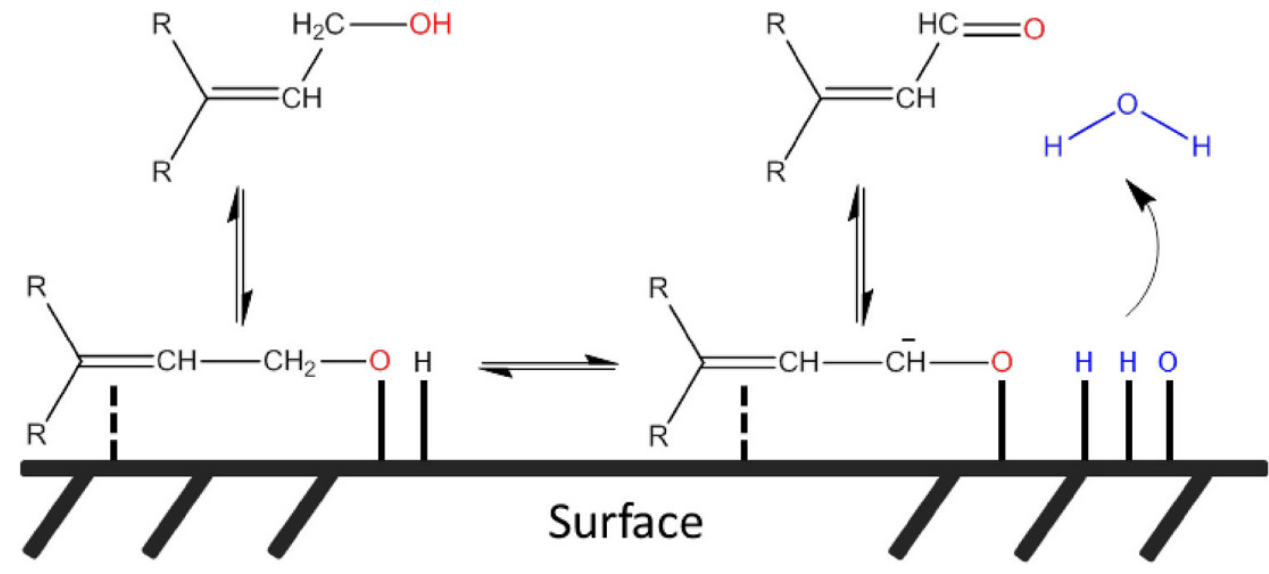

The past decade has seen significant progress in understanding the fundamental mode of action of Platinum Group Metal heterogeneous catalysts for aerobic selox and the associated reaction pathways and deactivation processes [41]. This insight has been aided by advances in analytical methodologies, notably the development of in situ or operando (under working conditions) spectroscopic [52-54] /microscopic [55-58] tools able to provide quantitative, spatio-temporal information on structurefunction relations of solid catalysts in the liquid and vapour phase. Parallel improvements in inorganic synthetic protocols offer finer control over preparative methods to direct the nanostructure (composition, morphology, size, valence and support architecture) of palladium catalysts [59-61] and thereby enhance activity, selectivity and lifetime in an informed manner. Ultimately, heterogeneous catalysts may offer significant advantages over homogeneous analogues in respect of initial catalyst cost, product separation, and metal recovery and recyclability [62]. Catalyst development can thus no longer be considered simply a matter of reaction kinetics, but as a clean technology wherein all aspects of process design, such as solvent selection, batch/ flow operation, catalyst recovery and waste production and disposal are balanced [63]. The efficacy of Platinum Group Metals (PGMs) surfaces towards the liquid phase oxidation of alcohols has been known for over 50 years [64], and the development of heterogeneous platinum selox catalysts (and more recently coinage metals such as gold [65, 66]) the subject of recent reviews [39, 67-69] hence only palladium selox catalysis is described herein.

\section{Heterogeneously catalysed routes to biodiesel}

Solid acid catalysed biodiesel synthesis

A wide range of inorganic and polymeric solid acids are commercially available, however, their application for the transesterification of oils into biodiesel has only been

operation in liquid organic solvents [47-51]. 
recently explored, in part reflecting their lower activity compared with base-catalysed routes [27], in turn necessitating higher reaction temperatures to deliver suitable conversions. While their activities are generally low, solid acids have the advantage that they are less sensitive to FFA contaminants than their solid base analogues, and hence can operate with unrefined feedstocks containing 3-6 wt $\%$ FFAs [27]. In contrast to solid bases which require feedstock pretreatment to remove fatty acid impurities, solid acids are able to esterify FFAs through to FAME in parallel with transesterification major TAG components without soap formation and thus reduce the number of processing steps to biodiesel [70-72].

Mesoporous silicas from the SBA family [73] have been examined for biodiesel synthesis, and include materials grafted with sulfonic acid groups $[74,75]$ or $\mathrm{SO}_{4} / \mathrm{ZrO}_{2}$ surface coatings [76]. Phenyl and propyl sulfonic acid SBA-15 catalysts are particularly attractive materials with activities comparable to Nafion and Amberlyst resins in palmitic acid esterification [77]. Phenylsulfonic acid functionalised silica is reportedly more active than their corresponding propyl analogues, in line with their respective acid strengths but is more difficult to prepare. Unfortunately, conventionally synthesised sulfonic acid functionalised SBA-15 silicas with pore sizes below $\sim 6 \mathrm{~nm}$ possess long, isolated parallel channels and suffer correspondingly slow in-pore diffusion and catalytic turnover in FFA esterification. However, poragens such as trimethylbenzene [78] triethylbenzene or triisopropylbenzene [79] can induce swelling of the Pluronic P123 micelles used to produce SBA-15, enabling ordered mesoporous silicas with diameters spanning 5-30 nm, and indeed ultra-large-pores with a BJH pore diameter as much as $34 \mathrm{~nm}$ [79]. This methodology was recently applied to prepare a range of large pore SBA-15 materials employing trimethylbenzene as the poragen, resulting in the formation of highly ordered periodic mesostructures with pore diameters of $\sim 6,8$ and $14 \mathrm{~nm}$ [80]. These silicas were subsequently functionalised by mercaptopropyl trimethoxysilane (MPTS) and oxidised with $\mathrm{H}_{2} \mathrm{O}_{2}$ to yield expanded $\mathrm{PrSO}_{3}$-SBA-15 catalysts which were effective in both palmitic acid esterification with methanol and tricaprylin and triolein transesterification with methanol under mild conditions. For both reactions, turnover frequencies dramatically increased with pore diameter, and all sulfonic acid heterogeneous catalysts significantly outperformed a commercial Amberlyst resin (Fig. 1). These rate enhancements are attributed to superior mass transport of the bulky FFA and triglycerides within the expanded $\mathrm{PrSO}_{3}-\mathrm{SBA}-15$. Similar observations have been made over Poly(styrenesulfonic acid)-functionalised ultra-large pore SBA-15 in the esterification of oleic acid with butanol [81].

Improving pore interconnectivity, for example through swapping the $p 6 \mathrm{~mm}$ architecture of SBA-15 for the Ia3d of KIT-6 was subsequently explored as an alternative means to enhance in-pore active site accessibility (Scheme 1) for FFA esterification [82]. KIT-6 mesoporous materials exhibit improved characteristics for biomolecule immobilisation [83] reflecting superior diffusion within the interconnected cubic structure. A family of pore-expanded propylsulfonic acid KIT-6 analogues were prepared via MPTS grafting and oxidation and screened for FFA

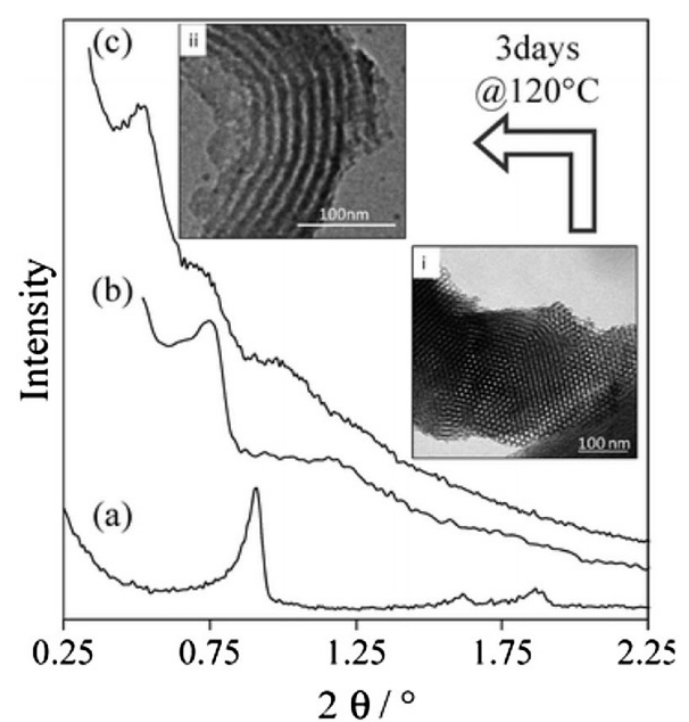

Fig. 1 (Left) Low angle powder X-ray diffraction patterns and transmission electron micrographs of propylsulfonic acid functionalised SBA-15 silicas as a function of pore diameter; and (right) corresponding catalytic activity in FFA esterification and TAG

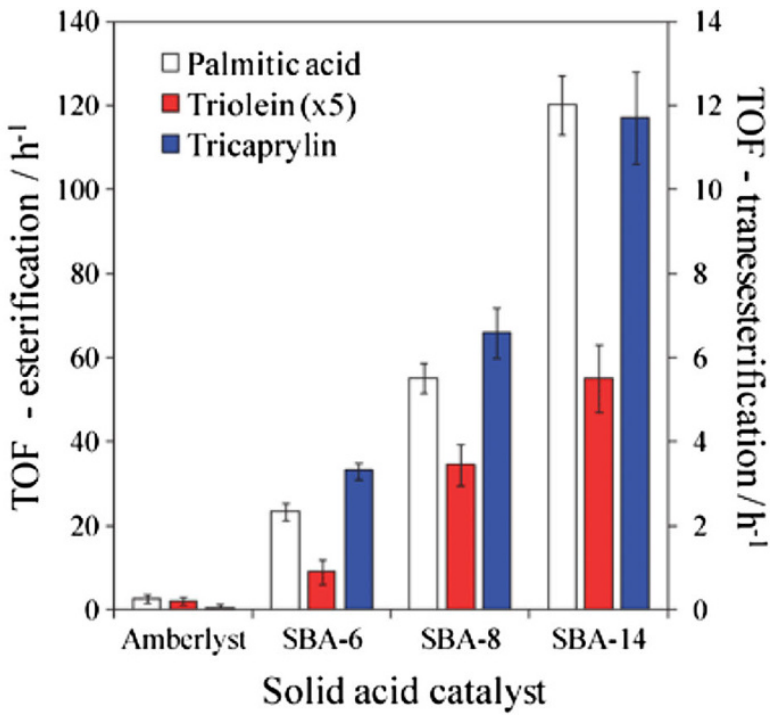

transesterification compared to a commercial solid acid resin. Adapted from reference [80] with permission from The Royal Society of Chemistry 


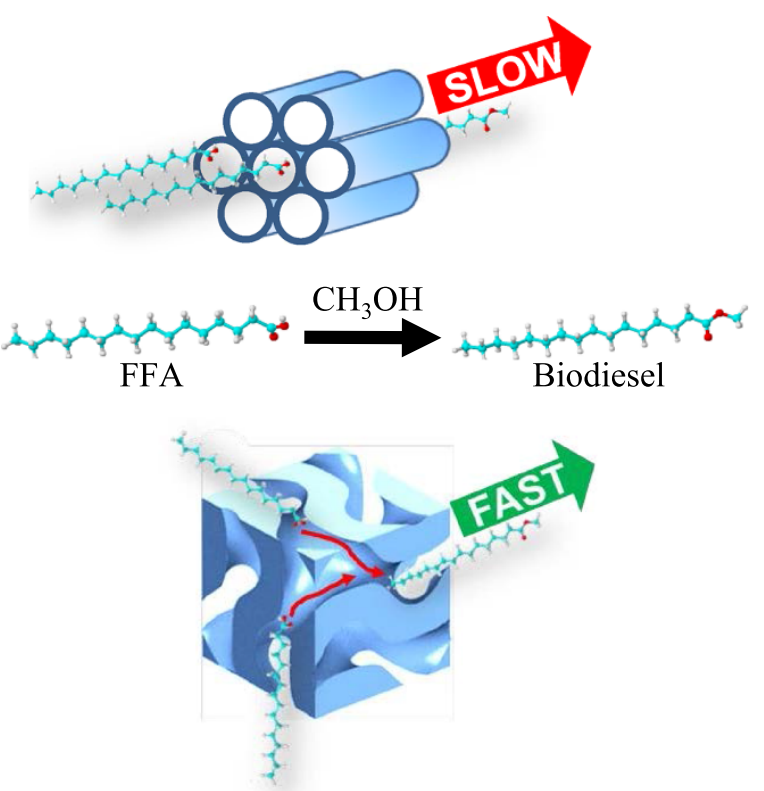

Fig. 2 Superior performance of interconnected, mesoporous propylsulfonic acid KIT-6 catalysts for biodiesel synthesis via FFA esterification with methanol versus non-interconnected mesoporous

esterification with methanol as a function of alkyl chain length under mild conditions. As-synthesised $\mathrm{PrSO}_{3} \mathrm{H}-$ KIT-6 exhibited respective 40 and $70 \%$ TOF enhancements toward propanoic and hexanoic acid esterification compared with a $\mathrm{PrSO}_{3} \mathrm{H}-\mathrm{SBA}-15$ analogue of comparable $(5 \mathrm{~nm})$ pore diameter as a consequence of the improved mesopore interconnectivity. However, pore accessibility remained rate-limiting for esterification of the longer chain lauric and palmitic acids. Hydrothermal aging protocols facilitated expansion of the KIT- 6 mesopore up to $7 \mathrm{~nm}$, with consequent doubling of TOFs for lauric and palmitic acid esterification versus $\mathrm{PrSO}_{3} \mathrm{H}-\mathrm{SBA}-15$ (Fig. 2).

While numerous solid acids have been applied for biodiesel synthesis [27, 32, 84], most materials exhibit microand/or mesoporosity which, as illustrated above, are not optimal for accommodating bulky $\mathrm{C}_{16}-\mathrm{C}_{18}$ TAGs of FFAs. For example, incorporation of a secondary mesoporosity into a microporous $\mathrm{H}-\beta$-zeolite to create a hierarchical solid acid significantly increased catalytic activity by lowering diffusion barriers [85]. Templated mesporous materials are widely used as catalyst supports [86, 87], with SBA-15 silicas popular candidates for reactions pertinent to biodiesel synthesis as previously discussed $[75,77,88]$. However, such surfactant-templated supports possessing long, isolated parallel and narrow channels are ill-suited to efficient in-pore diffusion of bio-oil feedstocks affording poor catalytic turnover. Further improvements in pore architecture are hence required to optimise mass transport of heavier bulky TAGs and FFAs commonly found in plant and algal oils. Simulations demonstrate that in the Knudsen

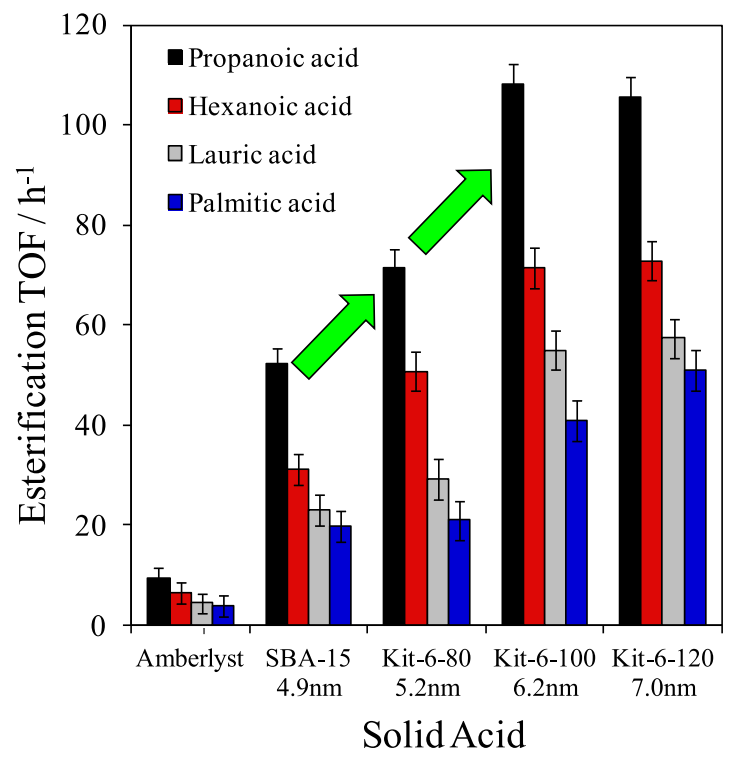

SBA-15 analogue. Adapted from reference [82]. Copyright 2012 American Chemical Society

diffusion regime [89], where reactants/products are able to diffuse enter/exit mesopores but experience moderate diffusion limitations, hierarchical pore structures may significantly improve catalyst activity. Materials with interpenetrating, bimodal meso-macropore networks have been prepared using microemulsion [90] or co-surfactant [91] templating routes and are particularly attractive for liquid phase, flow reactors wherein rapid pore diffusion is required. Liquid crystalline (soft) and colloidal polystyrene nanospheres (hard) templating methods have been combined to create highly organised, macro-mesoporous aluminas [92] and 'SBA-15 like' silicas [93] (Scheme 4), in which both macro- and mesopore diameters can be independently tuned over the range $200-500$ and 5-20 nm, respectively. The resulting hierarchical pore network of a propylsulfonic acid functionalised macro-mesoporous SBA-15 is shown in Fig. 3, wherein macropore incorporation confers a striking enhancement in the rates of tricaprylin transesterification and palmitic acid esterification with methanol, attributed to the macropores acting as transport conduits for reactants to rapidly access $\mathrm{PrSO}_{3} \mathrm{H}$ active sites located within the mesopores.

The hydrophilic nature of polar silica surfaces hinders their application for reactions involving apolar organic molecules. This is problematic for TAG transesterification (or FFA esterification) due to preferential in-pore diffusion and adsorption of alcohol versus fatty acid components. Surface hydroxyl groups also favour $\mathrm{H}_{2} \mathrm{O}$ adsorption, which if formed during FFA esterification can favour the reverse hydrolysis reaction and consequent low FAME 
Scheme 4 Liquid crystal and polystyrene nanosphere dual surfactant/physical templating route to hierarchical macroporous-mesoporous silicas

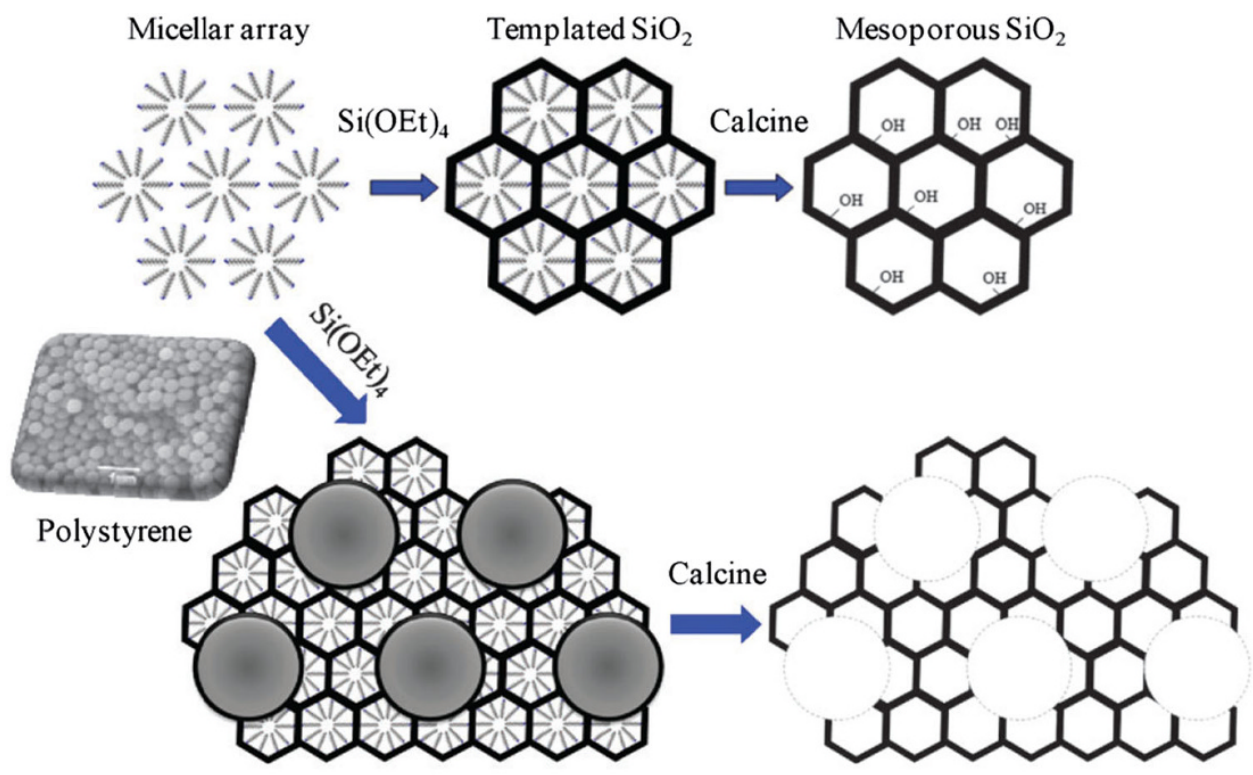

Templated macro-mesoporous $\mathrm{SiO}_{2}$

Macro-mesoporous $\mathrm{SiO}_{2}$
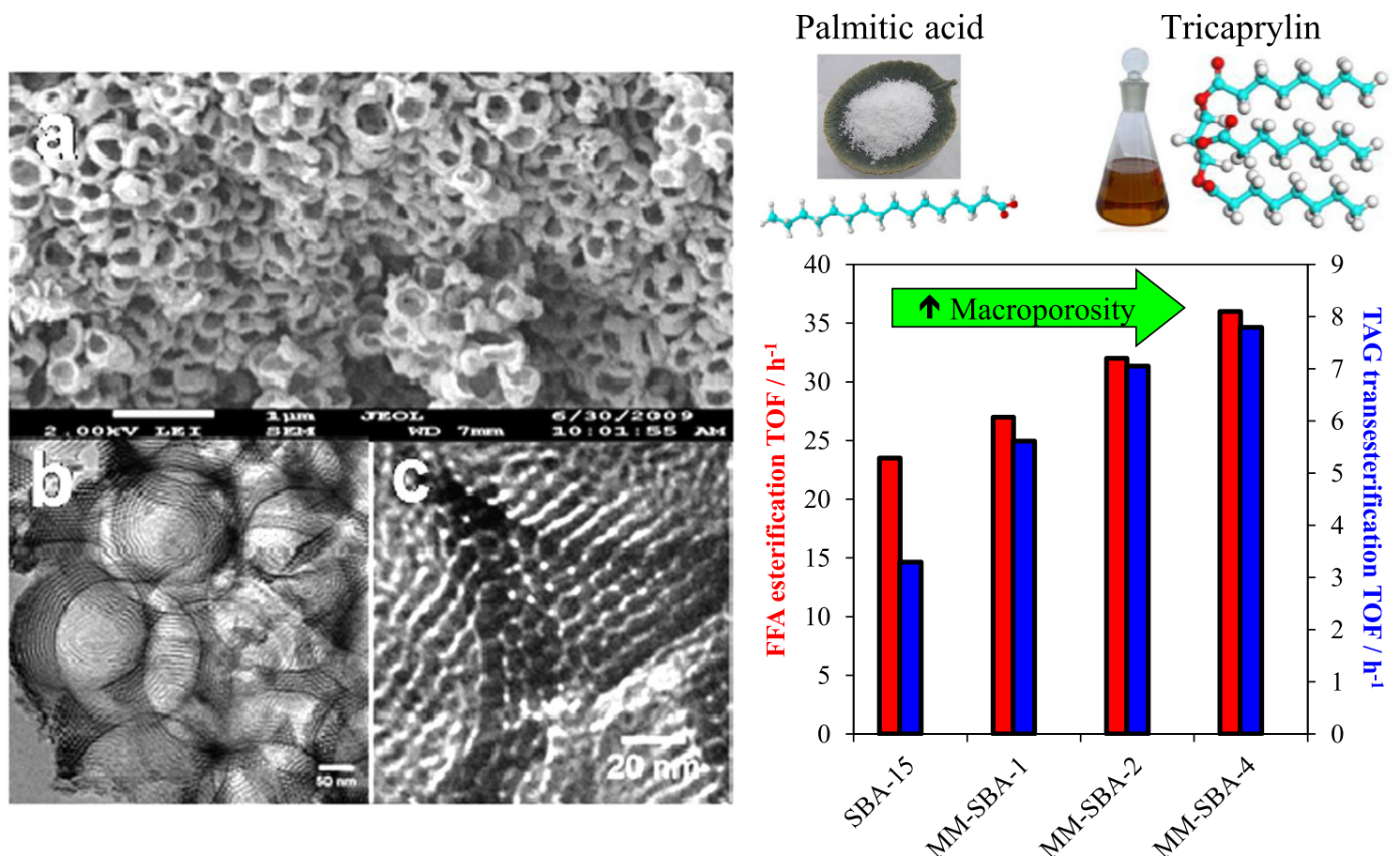

Fig. 3 (Left) SEM (a) and low and high magnification TEM (b, c) micrographs of a hierarchical macro-mesoporous $\mathrm{Pr}_{-} \mathrm{SO}_{3} \mathrm{H}-\mathrm{SBA}$ 15; (right) corresponding catalytic performance in palmitic acid esterification and tricaprylin transesterification with methanol as a

yields. Surface modification via the incorporation of organic functionality into polar oxide surfaces, or dehydroxylation, can lower their polarity and thereby increase initial rates of acid catalysed transformations of liquid phase organic molecules [94]. Surface polarity can also be tuned by incorporating alkyl/aromatic groups directly into function of macropore density versus a purely mesoporous $\mathrm{Pr}_{-} \mathrm{SO}_{3} \mathrm{H}-$ SBA-15. Adapted from reference [93] with permission from The Royal Society of Chemistry

the silica framework, for example polysilsesquioxanes can be prepared via the co-condensation of 1,4-bis(triethoxysilyl)benzene (BTEB), or 1,2-bis(trimethoxysilyl)-ethane (BTME), with TEOS and MPTS in the sol-gel process [95, 96] which enhances small molecule esterification [97] and etherification [98]. The incorporation of organic spectator 


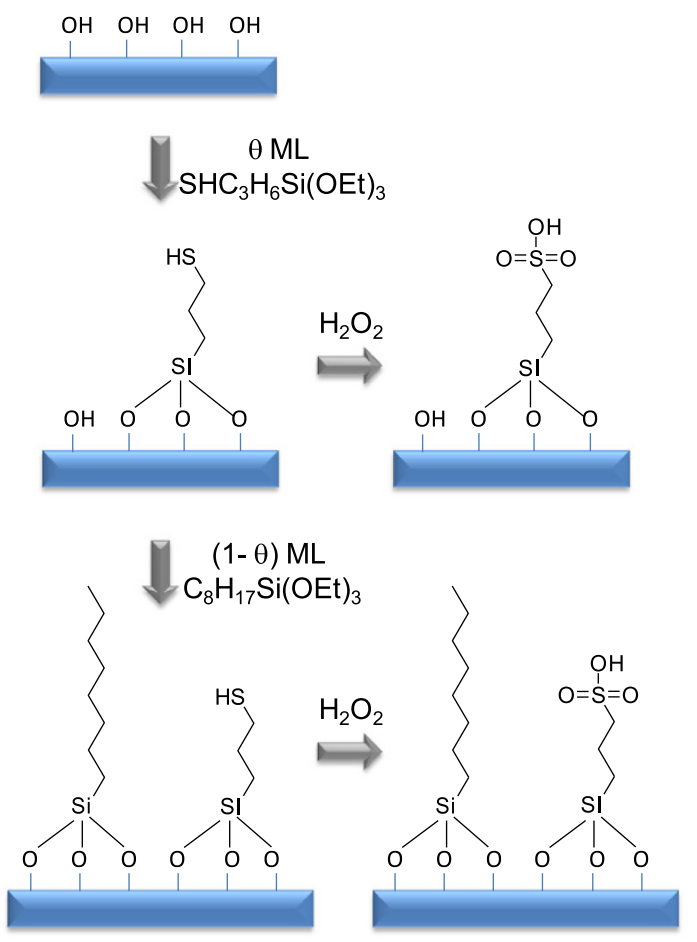

Scheme 5 Protocol for the synthesis of sulfonic acid and octyl cofunctionalised sulfonic acid MCM-41catalysts. Adapted from reference [101] with permission from The Royal Society of Chemistry

groups (e.g. phenyl, methyl or propyl) during the sol-gel syntheses of SBA-15 [99] and MCM-41 [100] sulphonic acid silicas is achievable via co-grafting or simple addition of the respective alkyl or aryltrimethoxysilane during cocondensation protocols. An experimental and computational study of sulphonic acid functionalised MCM-41 materials was undertaken to evaluate the effect of acid site density and surface hydrophobicity on catalyst acidity and associated performance [101]. MCM-41 was an excellent candidate due to the availability of accurate models for the pore structure from kinetic Monte Carlo simulations [102], and was modified with surface groups to enable dynamic simulation of sulphonic acid and octyl groups co-attached within the MCM-41 pores. In parallel experiments, two catalyst series were investigated towards acetic acid esterification with butanol (Scheme 5). In one series, the propylsulphonic acid coverage was varied between $\theta$ $\left(\mathrm{RSO}_{3} \mathrm{H}\right)=0-100 \%$ ML over the bare silica (MCM$\mathrm{SO}_{3} \mathrm{H}$ ). For the second octyl co-grafted series, both sulfonic acid and octyl coverages were tuned (MCM-Oc$\mathrm{SO}_{3} \mathrm{H}$ ). These materials allow the effect of lateral interactions between acid head groups and the role of hydrophobic octyl modifiers upon acid strength and activity to be separately probed.

To avoid diffusion limitations, butanol esterification with acetic acid was selected as a model reaction (Fig. 4). Ammonia calorimetry revealed that the acid strength of polar $\mathrm{MCM}-\mathrm{SO}_{3} \mathrm{H}$ materials increases from 87 to $118 \mathrm{~kJ} \mathrm{~mol}^{-1}$ with sulphonic acid loading. Co-grafted octyl groups dramatically enhance the acid strength of MCM-Oc- $\mathrm{SO}_{3} \mathrm{H}$ for submonolayer $\mathrm{SO}_{3} \mathrm{H}$ coverages, with $\Delta \mathrm{H}_{\mathrm{ads}}\left(\mathrm{NH}_{3}\right)$ rising to $103 \mathrm{~kJ} \mathrm{~mol}^{-1}$. The per site activity of the $\mathrm{MCM}-\mathrm{SO}_{3} \mathrm{H}$ series in butanol esterification with acetic acid mirrors their acidity, increasing with $\mathrm{SO}_{3} \mathrm{H}$ content. Octyl surface functionalisation promotes esterification for all $\mathrm{MCM}-\mathrm{Oc}-\mathrm{SO}_{3} \mathrm{H}$ catalysts, doubling the turnover frequency of the lowest loading $\mathrm{SO}_{3} \mathrm{H}$ material. Molecular dynamic simulations indicate that the interaction of isolated sulphonic acid moieties with surface silanol groups is the primary cause of the lower acidity and activity of submonolayer samples within the MCM- $\mathrm{SO}_{3} \mathrm{H}$ series. Lateral interactions with octyl groups help to reorient sulphonic acid headgroups into the pore interior, thereby enhancing acid strength and associated esterification activity.

In summary, recent developments in tailoring the structure and surface functionality of sulfonic acid silicas have led to a new generation of tunable solid acid catalysts well-suited to the esterification of short and long chain FFAs, and transesterification of diverse TAGs, with methanol under mild reaction conditions. A remaining challenge is to extend the dimensions and types of poreinterconnectivities present within the host silica frameworks, and to find alternative low cost soft and hard templates to facilitate synthetic scale-up of these catalysts for multi-kg production. Surfactant template extraction is typically achieved via energy-intensive solvent reflux, which results in significant volumes of contaminated waste and long processing times, while colloidal templates often require high temperature calcination which prevents template recovery/re-use and releases carbon dioxide. Preliminary steps towards the former have been recently taken, employing room temperature ultrasonication in a small solvent volume to deliver effective extraction of the P123 Pluronic surfactant used in the preparation of SBA-15 in only 5 min, with a $99.9 \%$ energy saving and $90 \%$ solvent reduction over reflux methods, and without compromising textural, acidic or catalytic properties of the resultant $\mathrm{Pr}$ $\mathrm{SO}_{3} \mathrm{H}-\mathrm{SBA}-15$ in hexanoic acid esterification (Fig. 5) [103].

Solid base-catalysed biodiesel synthesis

Base catalysts are generally more active than acids in transesterification, and hence are particularly suitable for high purity oils with low FFA content. Biodiesel synthesis using a solid base catalyst in continuous flow, packed bed arrangement would facilitate both catalyst separation and co-production of high purity glycerol, thereby reducing production costs and enabling catalyst re-use. Diverse solid 
Fig. 4 (Left) Molecular dynamics simulations of MCM$\mathrm{SO}_{3} \mathrm{H}$ and $\mathrm{MCM}-\mathrm{Oc}-\mathrm{SO}_{3} \mathrm{H}$ pore models highlighting the interaction between surface sulfonic acid and hydroxyl groups in the absence of cografted octyl chains; (right) influence of $\mathrm{PrSO}_{3} \mathrm{H}$ surface density and co-grafted octyl groups on catalytic performance in acetic acid esterification with butanol. Adapted from reference [101] with permission from The Royal Society of Chemistry
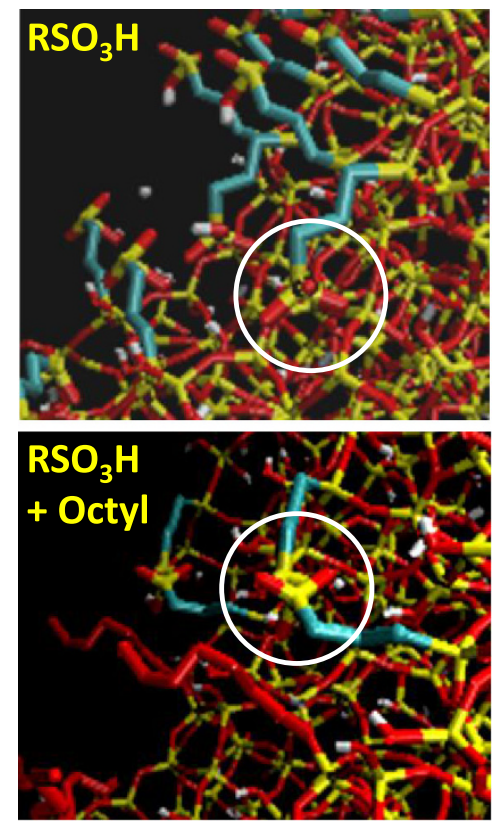
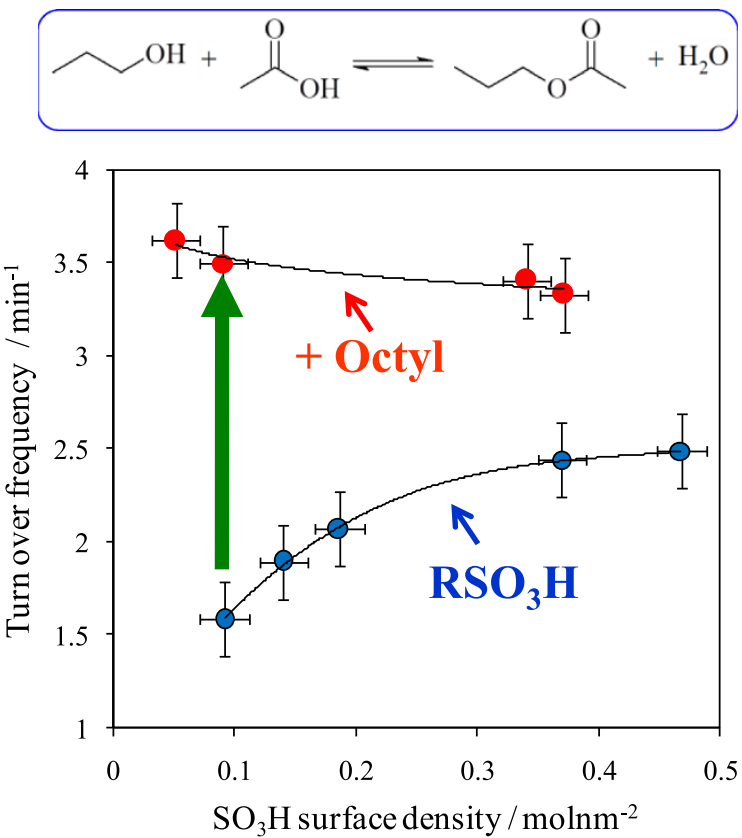

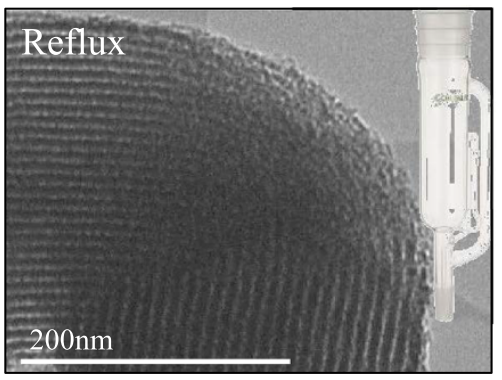

$24 \mathrm{~h}, 3600 \mathrm{~W}$ $100 \mathrm{ml} \mathrm{MeOH} . \mathrm{g}_{\text {cat }}{ }^{-1}$
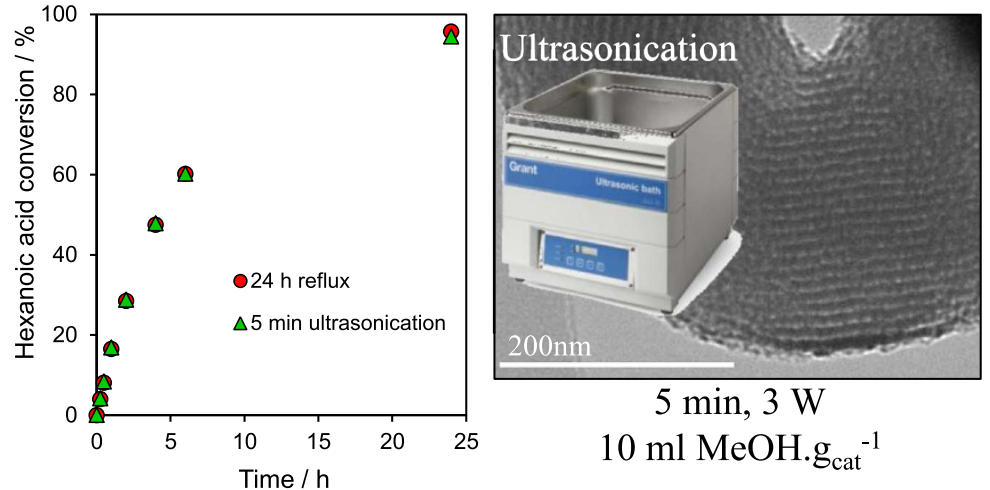

$5 \mathrm{~min}, 3 \mathrm{~W}$

$10 \mathrm{ml} \mathrm{MeOH} \cdot \mathrm{g}_{\text {cat }}{ }^{-1}$
Fig. 5 Surfactant template extraction via energy/atom-efficient ultrasonication delivers a one-pot $\mathrm{PrSO}_{3} \mathrm{H}-\mathrm{SBA}-15$ solid acid catalyst with identical structure and reactivity to that obtained by conventional, inefficient reflux. Adapted from reference [103] with permission from The Royal Society of Chemistry

problem encountered in metal catalysed biodiesel production which hampers commercialisation [110].

Alkali-doped $\mathrm{CaO}$ and $\mathrm{MgO}$ have also been investigated for TAG transesterification [111-113], with their enhanced basicity attributed to the genesis of $\mathrm{O}^{-}$centres following the replacement of $\mathrm{M}^{+}$for $\mathrm{M}^{2+}$ and associated charge imbalance and concomitant defect generation. Optimum activity for Li-doped $\mathrm{CaO}$ occurs when a saturated $\mathrm{Li}^{+}$ monolayer is formed (Fig. 6) [113], although leaching of the alkali promoter remains problematic [114].

It is widely accepted that the catalytic activity of alkaline earth oxide catalysts is very sensitive to their preparation, and corresponding surface morphology and/ or defect density. For example, Parvulescu and Richards demonstrated the impact of the different $\mathrm{MgO}$ crystal facets upon the transesterification of sunflower oil by 


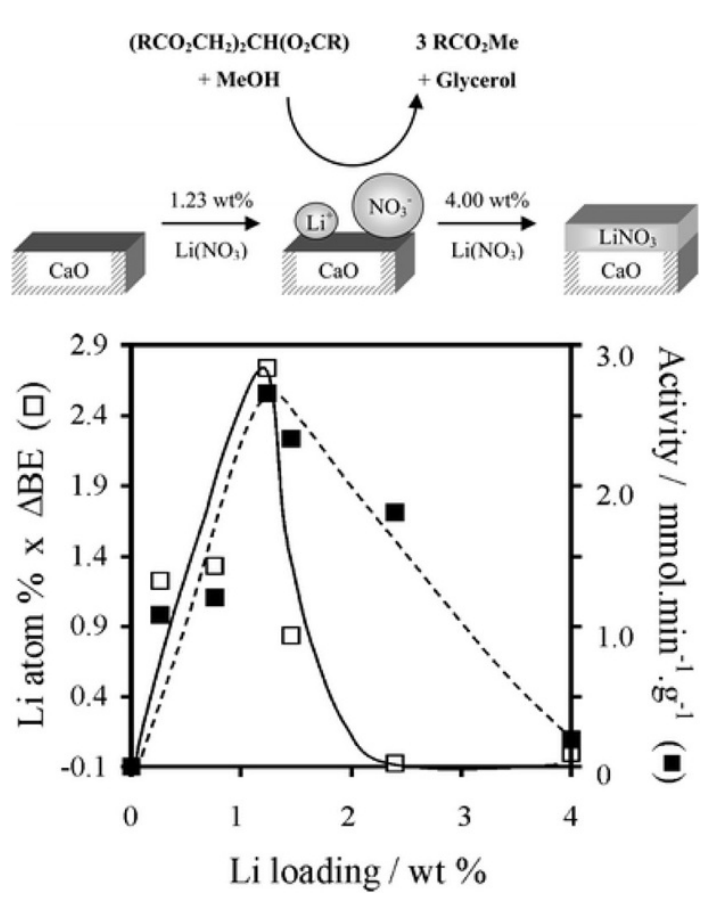

Fig. 6 Correlation between evolving surface composition, density of electronically perturbed $\mathrm{Li}^{+}$sites, and corresponding activity in tributyrin transesterification with methanol over $\mathrm{Li}$-doped $\mathrm{CaO}$ as a function of Li loading. Adapted from reference [113] with permission from The Royal Society of Chemistry

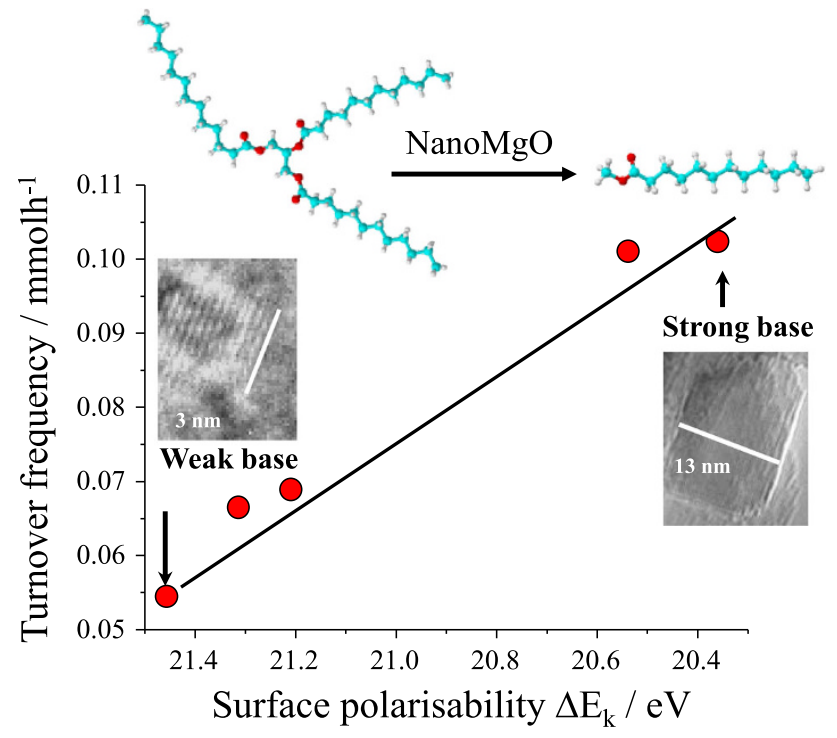

Fig. 7 Relationship between surface polarisability of $\mathrm{MgO}$ nanocrystals and their turnover frequency towards tributyrin transesterifcation. Adapted from reference [117] with permission from The Royal Society of Chemistry

comparing nanoparticles [115] versus (111) terminated nanosheets [116]. Chemical titration reveals that both morphologies possess two types of base sites, with the nanosheets exhibiting well-defined, medium-strong basicity consistent with their uniform exposed facets and

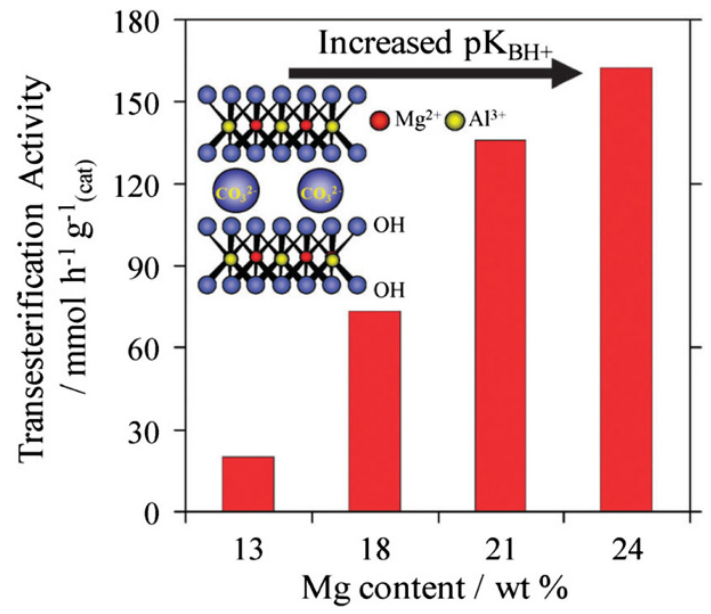

Fig. 8 Impact of $\mathrm{Mg}: \mathrm{Al}$ hydrotalcite surface basicity on their activity towards tributyrin transesterification. Adapted from reference [118] with permission from Elsevier

which confer higher FAMe yields during sunflower oil transesterification. Subsequent synthesis, screening and spectroscopic characterisation of a family of size-/shapecontrolled $\mathrm{MgO}$ nanoparticles prepared via a hydrothermal synthesis revealed small $(<8 \mathrm{~nm})$ particles terminate in high coordination (100) facets, and exhibit both weak polarisability and poor activity in tributyrin transesterification with methanol [117]. Calcination drives restructuring and sintering to expose lower coordination stepped (111) and (110) surface planes, which are more polarisable and exhibit much higher transesterification activities under mild conditions. A direct correlation was therefore observed between the surface electronic structure and associated catalytic activity, revealing a pronounced structural preference for (110) and (111) facets (Fig. 7).

Hydrotalcites are another class of solid base catalysts that have attracted recent attention because of their high activity and robustness in the presence of water and FFA $[118,119]$. Hydrotalcites $\left(\left[\mathrm{M}(\mathrm{III})_{1}{ }_{x} \mathrm{M}(\mathrm{III})_{x}(\mathrm{OH})_{2}\right]^{x+}\right.$ $\left(\mathrm{A}_{x / n}^{n-}\right) \mathrm{mH}_{2} \mathrm{O}$ ) adopt a layered double hydroxide structure with brucite-like $\operatorname{Mg}(\mathrm{OH})_{2}$ ) hydroxide sheets containing octahedrally coordinated $\mathrm{M}^{2+}$ and $\mathrm{M}^{3+}$ cations and $\mathrm{A}^{n-}$ anions between layers to balance the overall charge [120], and are conventionally synthesised via co-precipitation from their nitrates using alkalis as both $\mathrm{pH}$ regulators and a carbonate source. $\mathrm{Mg}-\mathrm{Al}$ hydrotalcites have been applied for TAG transesterification of poor and high quality oil feeds [121] such as refined and acidic cottonseed oil (9.5 wt $\%$ FFA), and animal fat feed ( $45 \mathrm{wt} \%$ water), delivering $99 \%$ conversion within $3 \mathrm{~h}$ at $200{ }^{\circ} \mathrm{C}$. It is important to note that many catalytic studies employing hydrotalcites for transesterification are suspect due to their use of $\mathrm{Na}$ or $\mathrm{K}$ hydroxide/carbonate solutions to precipitate 


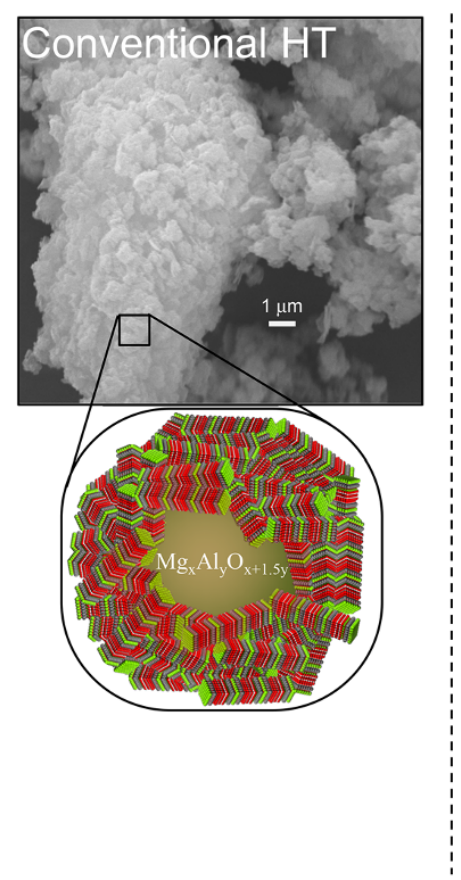

Fig. 9 Superior catalytic performance of a hierarchical macroporous-microporous $\mathrm{Mg}-\mathrm{Al}$ hydrotalcite solid base catalyst for TAG transesterification to biodiesel versus a conventional microporous

the hydrotalcite phase. Complete removal of alkali residues from the resulting hydrotalcites is inherently difficult, resulting in parallel ill-defined homogeneous contributions to catalysis arising from leached $\mathrm{Na}$ or $\mathrm{K}[122,123]$. This problem has been overcome by the development of alkalifree precipitation routes using $\mathrm{NH}_{3} \mathrm{OH}$ and $\mathrm{NH}_{3} \mathrm{CO}_{3}$, offering well-defined thermally activated and rehydrated $\mathrm{Mg}-\mathrm{Al}$ hydrotalcites with compositions spanning $x=0.25-0.55$ [118]. Spectroscopic measurements reveal that increasing the $\mathrm{Mg}: \mathrm{Al}$ ratio enables the surface charge and accompanying base strength to be systematically enhanced, with a concomitant increase in the rate of tributyrin transesterification under mild reaction conditions (Fig. 8).

In spite of their promise for biodiesel production, conventionally prepared hydrotalcites are microporous, and hence poorly suited to application in the transesterification of bulky $\mathrm{C}_{16}-\mathrm{C}_{18}$ TAG components of bio-oils. This problem was recently tackled by adopting the same hard templating method utilising polystyrene nanospheres described in Scheme 4 to incorporate macroporosity, and thus create a hierarchical macroporous-microporous hydrotalcite solid base catalyst [124]. The introduction of macropores as 'superhighways' to rapidly transport heavy TAG oil components to active base sites present at (high aspect ratio) hydrotalcite nanocrystallites, dramatically enhanced turnover frequencies for triolein transesterification compared with that achievable over an analogous $\mathrm{Mg}_{-}$ analogue. Adapted from reference [124] with permission from The Royal Society of Chemistry

Al microporous hydrotalcite (Fig. 9), reflecting superior mass transport through the hierarchical catalyst.

In terms of sustainability, it is important to find low cost routes to the synthesis of solid base catalysts that employ earth abundant elements. Dolomitic rock, comprising alternating $\mathrm{Mg}\left(\mathrm{CO}_{3}\right)-\mathrm{Ca}\left(\mathrm{CO}_{3}\right)$ layers, is structurally very similar to calcite $\left(\mathrm{CaCO}_{3}\right)$, with a high natural abundance and low toxicity, and in the UK is sourced from quarries working Permian dolomites in Durham, South Yorkshire and Derbyshire [125]. In addition to uses in agriculture and construction, dolomite finds industrial applications in iron and steel production, glass manufacturing and as fillers in plastics, paints, rubbers, adhesives and sealants. Catalytic applications for powdered, dolomitic rock offer the potential to further valorise this readily available waste mineral, and indeed dolomite has shown promise in biomass gasification [126] as a cheap, disposable and naturally occurring material that significantly reduces the tar content of gaseous products from gasifiers. Dolomite has also been investigated as a solid base catalyst in biodiesel synthesis [127], wherein fresh dolomitic rock comprised approximately $77 \%$ dolomite and $23 \%$ magnesian calcite. High temperature calcination induced $\mathrm{Mg}$ surface segregation, resulting in $\mathrm{MgO}$ nanocrystals dispersed over $\mathrm{CaO} /(\mathrm{OH})_{2}$ particles, while the attendant loss of $\mathrm{CO}_{2}$ increases both the surface area and basicity. The resulting calcined dolomite proved an effective catalyst for the transesterification of $\mathrm{C}_{4}$, $\mathrm{C}_{8}$ and TAGs with methanol and longer chain $\mathrm{C}_{16-18}$ 


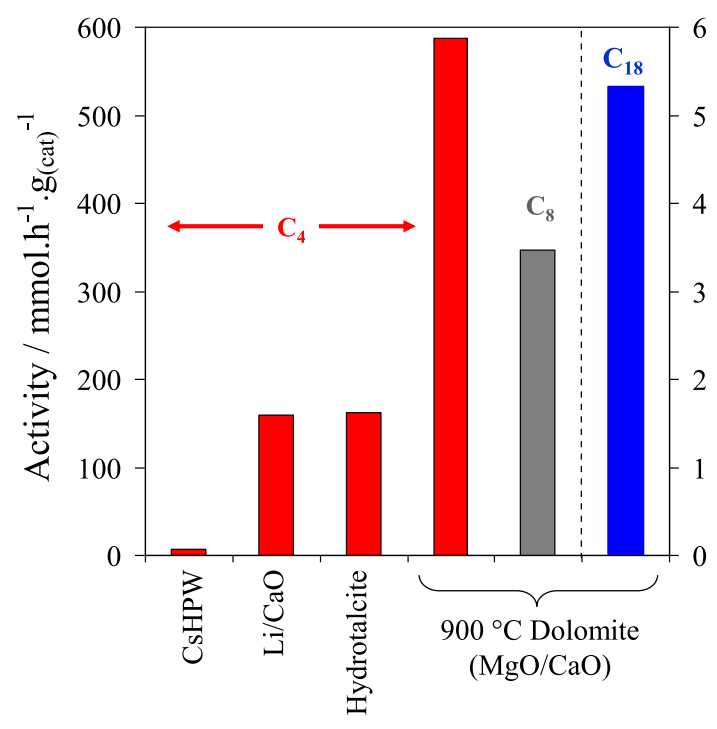

Fig. 10 Catalytic activity of calcined Dolomite for the transesterification of short and long chain TAGs with methanol benchmarked against literature solid acid and base catalysts. Reproduced from reference [127] with permission from The Royal Society of Chemistry

components present within olive oil, with TOFs for tributyrin conversion to methyl butanoate the highest reported for any solid base (Fig. 10). The slower transesterification rates for bulkier TAGs were attributed to diffusion limitations in their access to base sites. Calcined dolomite has also shown promise in the transesterification of canola oil with methanol, achieving $92 \%$ FAME after $3 \mathrm{~h}$ reaction with 3 wt\% catalyst [128].

In summary, a host of inorganic solid base catalysts have been developed for the low temperature transesterification of triglyceride components of bio-oil feedstocks, offering activities far superior to those achieved via alternative solid acid catalysts to date. However, leaching of alkali and alkaline earth elements and associated catalyst recycling remains a challenge, while improved resilience to water and fatty acid impurities in plant, algal and waste oils feedstocks is required to eliminate additional esterification pre-treatments. To date, only a handful of biodiesel production processes employing heterogeneous catalysts have been commercialised, notably the Esterfip-H process developed by Axens and IFP which utilises a mixture of $\mathrm{ZnO}$ and alumina and is operated on a 200 kton per annum scale with parallel production of high quality glycerine [129].

\section{Palladium catalysed aerobic alcohol selox}

Particle size effects

Within nanocatalysis, the particle size is a well-documented key parameter influencing both activity and selectivity. This reflects the combination of quantum and geometric effects associated with the respective evolution of electronic properties from atomic like to delocalised bands, and shifting population of low to high coordination surface atoms, with increasing nanoparticle size and dimensionality. Kaneda et al. [130] hypothesised that the unique reactivity of 2060 atom Pd clusters supported on titania towards aromatic alcohol selox arose from a distribution of $\mathrm{Pd}^{0}, \mathrm{Pd}^{+}$and $\mathrm{Pd}^{2+}$ surfaces sites, with $\pi$-bonding interactions between the phenyl group and $\mathrm{Pd}^{2+}$ species facilitating subsequent oxidative addition of the $\mathrm{O}-\mathrm{H}$ bond by neighbouring $\mathrm{Pd}^{0}$ and eventual $\beta$-hydride elimination. Surface hydride was hypothesised to react with oxygen from a neighbouring $\mathrm{Pd}_{2} \mathrm{O}$ centre forming $\mathrm{H}_{2} \mathrm{O}$ and regenerating the metal site. Optimal activity for cinnamyl alcohol selox to cinnamaldehyde coincided with clusters possessing the maximum fraction of $\mathrm{Pd}^{+}$character.

Particle size dependency was also reported for the catalytic transformation of benzyl alcohol over Pd nanoparticles dispersed on alumina, $\mathrm{SiO}_{2}$ and $\mathrm{NaX}$ zeolite supports $[131,132]$. For $\mathrm{Pd} / \mathrm{NaX}$ and $\mathrm{Pd} / \mathrm{SiO}_{2}-\mathrm{Al}_{2} \mathrm{O}_{3}$, benzyl alcohol selox was fastest over particles between 3 and $5 \mathrm{~nm}$, whereas geraniol and 2-octanol were structure-insensitive. Systematic studies of particle size effects in cinnamyl and crotyl alcohol selox over amorphous and mesostructured alumina and silica supports have likewise uncovered pronounced size effects in both initial selox rates and TOFs [133-136], which increase monotonically with shrinking nanoparticle diameters (even down to single atoms) [137]. HAADF-STEM analysis reveals atomically dispersed palladium exhibits maximal rates towards benzyl, cinnamyl and crotyl alcohols, with selectivities to their corresponding aldehydes $>70 \%$. The origin of such size effects is revisited below. The use of colloidal Pd nanoclusters for aqueous phase alcohol selox is limited [138-140], wherein Pd aggregation and Pd black formation hinders catalytic performance. However, the successful stabilisation of $3.6 \mathrm{~nm}$ Pd nanoclusters is reported using an amphiphilic nonionic triblock copolymer, Pluronic P123; in the selective oxidation of benzyl alcohol, $100 \%$ aldehyde selectivity and high selox rates are achievable, with high catalytic activity maintained with negligible sintering after 13 recycling reactions [141].

Surface reaction mechanism

The rational design and optimisation of palladium selox catalysts require a microscopic understanding of the active catalytic species responsible for alcohol and oxygen activation, and the associated reaction pathway to the aldehyde/ketone products and any competing processes. A key characteristic of palladium is its ability to perform selox chemistry at temperatures between 60 and $160{ }^{\circ} \mathrm{C}$ and with

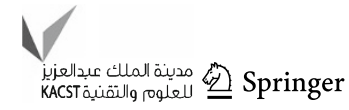




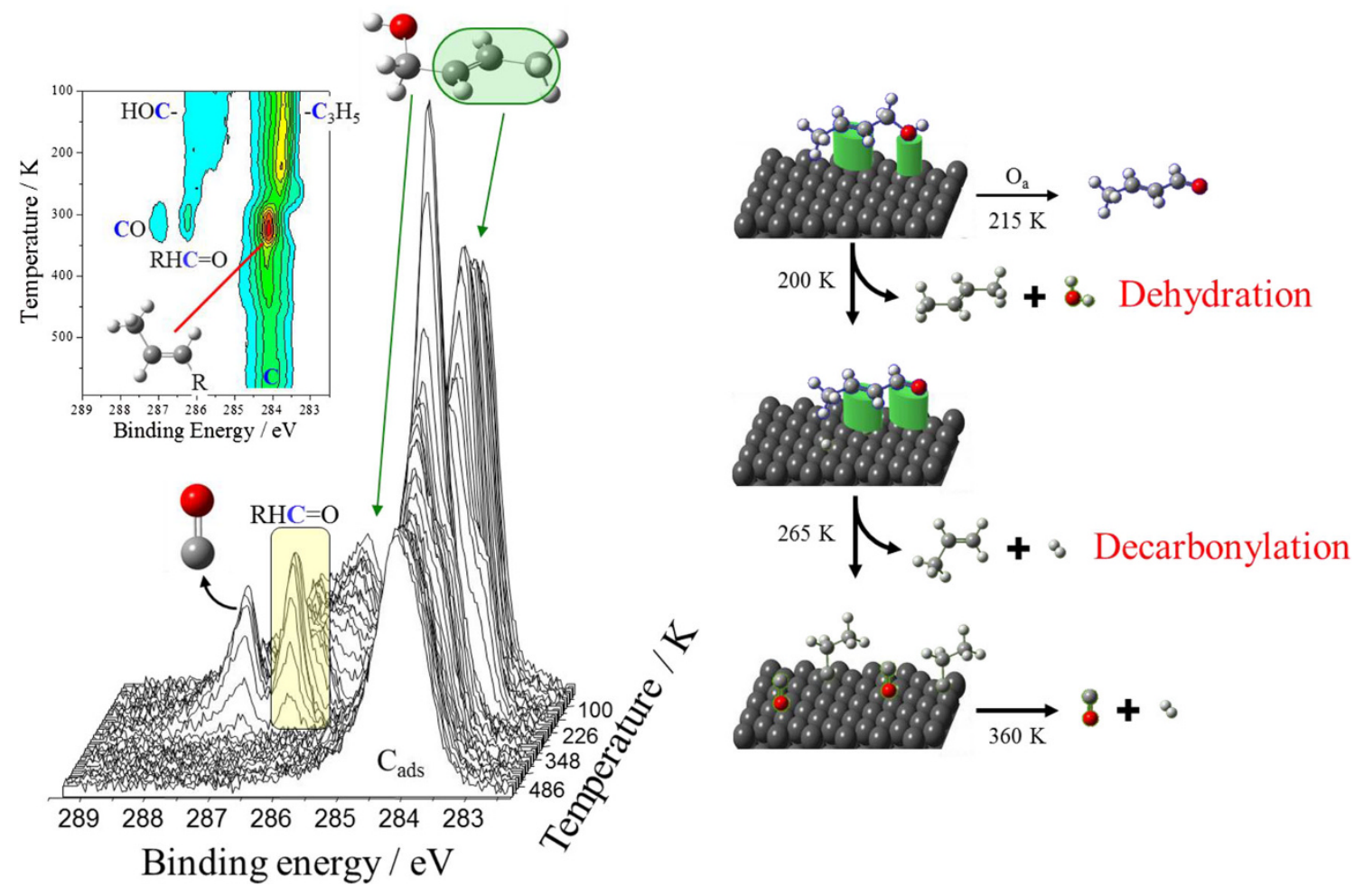

Fig. 11 Temperature-programmed C 1s XP spectra of a reacting crotyl alcohol adlayer over Pd(111) highlighting the primary dehydrogenation pathway and competing decarbonylation pathways. Adapted from reference [143]. Copyright 2007 American Chemical Society

ambient oxygen pressure $[39,142]$ via the wi dely accepted oxidative dehydrogenation route illustrated in Scheme 3 $[39,67]$. Whether $\mathrm{O}-\mathrm{H}$ or $\mathrm{C}-\mathrm{H}$ scission of the $\alpha$-carbon is the first chemical step remains a matter of debate, since the only fundamental studies over well-defined Pd(111) surfaces to date employed temperature-programmed XPS [143] and metastable de-excitation spectroscopy (MDS) [144] with temporal resolutions on the second $\rightarrow$ minute timescale, over which loss of both hydrogens appears coincident. However, temperature-programmed mass spectrometric [145] and vibrational [146] studies of unsaturated $\mathrm{C}_{1}-\mathrm{C}_{3}$ alcohols implicate $\mathrm{O}-\mathrm{H}$ cleavage and attendant alkoxy formation over Pd single crystal surfaces as the first reaction step [142, 147]. It is generally held that the resultant hydrogen adatoms react with dissociatively absorbed oxygen to form water, which immediately desorbs at ambient temperature thereby shifting the equilibrium to carbonyl formation [39, 67]. Temperatureprogrammed XPS studies of crotyl alcohol adsorbed over clean $\operatorname{Pd}(111)$ [143] prove that oxidative dehydrogenation to crotonaldehyde occurs at temperatures as low as $-60{ }^{\circ} \mathrm{C}$ (Fig. 11), with alcohol dehydration to butane only a minor pathway. These ultra-high vacuum measurements also revealed that reactively formed crotonaldehyde undergoes a competing decarbonylation reaction over metallic palladium above $0{ }^{\circ} \mathrm{C}$ yielding strongly bound $\mathrm{CO}$ and propylidene which may act as site-blockers poisoning subsequent catalytic selox cycles, coincident with evolution of propene into the gas phase. Unexpectedly, preadsorbed atomic oxygen switched-off undesired decarbonylation chemistry, promoting facile crotonaldehyde desorption.

Nature of the active site

The preceding observation that surface oxygen is not only critical for the removal of hydrogen adatoms but also to suppress decarbonylation of selox products over metallic palladium is in excellent agreement with an in situ ATR-IR study of cinnamyl alcohol selox over $\mathrm{Pd} / \mathrm{Al}_{2} \mathrm{O}_{3}$ [148]. In related earlier investigations employing aqueous electrochemical protocols, the same researchers postulated that oxidative dehydrogenation of alcohols requires PGM catalysts in a reduced state, hypothesising that 'over-oxidation' was responsible for deactivation of palladium selox catalysts [69]. A subsequent operando X-ray absorption spectroscopy (XAS) study by Grunwaldt et al. [150], bearing remarkable similarity to an earlier study to the author of this review [149], evidenced in situ reduction of oxidised palladium in an as-prepared $\mathrm{Pd} / \mathrm{Al}_{2} \mathrm{O}_{3}$ catalyst during cinnamyl alcohol oxidation within a continuous flow fixed-bed reactor. Unfortunately the reaction kinetics 
were not measured in parallel to explore the impact of palladium reduction, however, a follow-up study of 1-phenylethanol selox employing the same reactor configuration (and oxygen-deficient conditions) evidenced a strong interplay between selox conversion/selectivity and palladium oxidation state [151]. It was concluded that metallic Pd was the catalytically active species, an assertion re-affirmed in subsequent in situ ATR-IR/XAS measurements of benzyl [152-154] and cinnamyl alcohol [155] selox in toluene and under supercritical $\mathrm{CO}_{2}$, respectively, wherein the $\mathrm{C}=\mathrm{O}$ stretching intensity was assumed to track alcohol conversion. It is interesting to note that the introduction of oxygen to the reactant feed in these infrared studies dramatically improved alcohol conversion/aldehyde production (Fig. 12), which was attributed to hydrogen abstraction from the catalyst surface $[156,157]$ rather than to a change in palladium oxidation state. In contrast to their liquid phase experiments, high pressure XANES and EXAFS measurements of $\mathrm{Pd} / \mathrm{Al}_{2} \mathrm{O}_{3}$ catalysed benzyl alcohol selox under supercritical $\mathrm{CO}_{2}$ led Grunwaldt and Baiker to conclude that maximum activity arose from particles mainly oxidised in the surface/shelfedge [48].

In a parallel research programme, the author's group systematically characterised the physicochemical properties of palladium nanoparticles as a function of size over non-reducible supports to quantify structure-function relations in allylic alcohol selox [133-137, 158, 159]. The combination of XPS and XAS measurements revealed that freshly prepared alumina $[134,137]$ and silica $[135,158]$ supported nanoparticles are prone to oxidation as their diameter falls below $\sim 4 \mathrm{~nm}$, with the fraction of $\mathrm{PdO}$ proportional to the support surface area and interconnectivity. Complementary kinetic analyses uncovered a direct correlation between the surface PdO content and activity/ TOFs towards cinnamyl and crotyl alcohol selox [134, 137]. Operando liquid phase $\mathrm{XAS}$ of $\mathrm{Pd} / \mathrm{C}$ and $\mathrm{Pd} / \mathrm{Al}_{2} \mathrm{O}_{3^{-}}$ SBA-15 catalysts during cinnamyl alcohol selox evidenced in situ reduction of PdO (Fig. 13), however, by virtue of simultaneously measuring the rate of alcohol selox, Lee et al. were able to prove that this oxide $\rightarrow$ metal structural transition was accompanied by coincident deactivation. Together these findings strongly implicate a (surface) $\mathrm{PdO}$ active phase, consistent with surface science predictions that metallic palladium favours aldehyde decarbonylation and consequent self-poisoning by $\mathrm{CO}$ and organic residues $[143,160]$, akin to that reported during fatty acid decarboxylation over Pd/MCF [161].

To conclusively establish whether oxide or metal is responsible for alcohol selox catalysed by dispersed palladium nanoparticles, a multi-dimensional spectroscopic investigation of vapour phase crotyl alcohol selox was undertaken (since XAS is an averaging technique a complete understanding of catalyst operation requires multiple analytical techniques [162-164]). Synchronous, timeresolved DRIFTS/MS/XAS measurements of supported and colloidal palladium were performed in a bespoke environmental cell [165] to simultaneously interrogate adsorbates on the catalyst surface, Pd oxidation state and reactivity under transient conditions in the absence of competitive solvent effects [166, 167]. Under mild reaction
Fig. 12 Impact of oxygen on the selective oxidation of (top left) cinnamyl alcohol; (bottom left) 1-phenylethanol; and (right) 2-octanol. Adapted from references [148, 151, 154] with permission from Elsevier
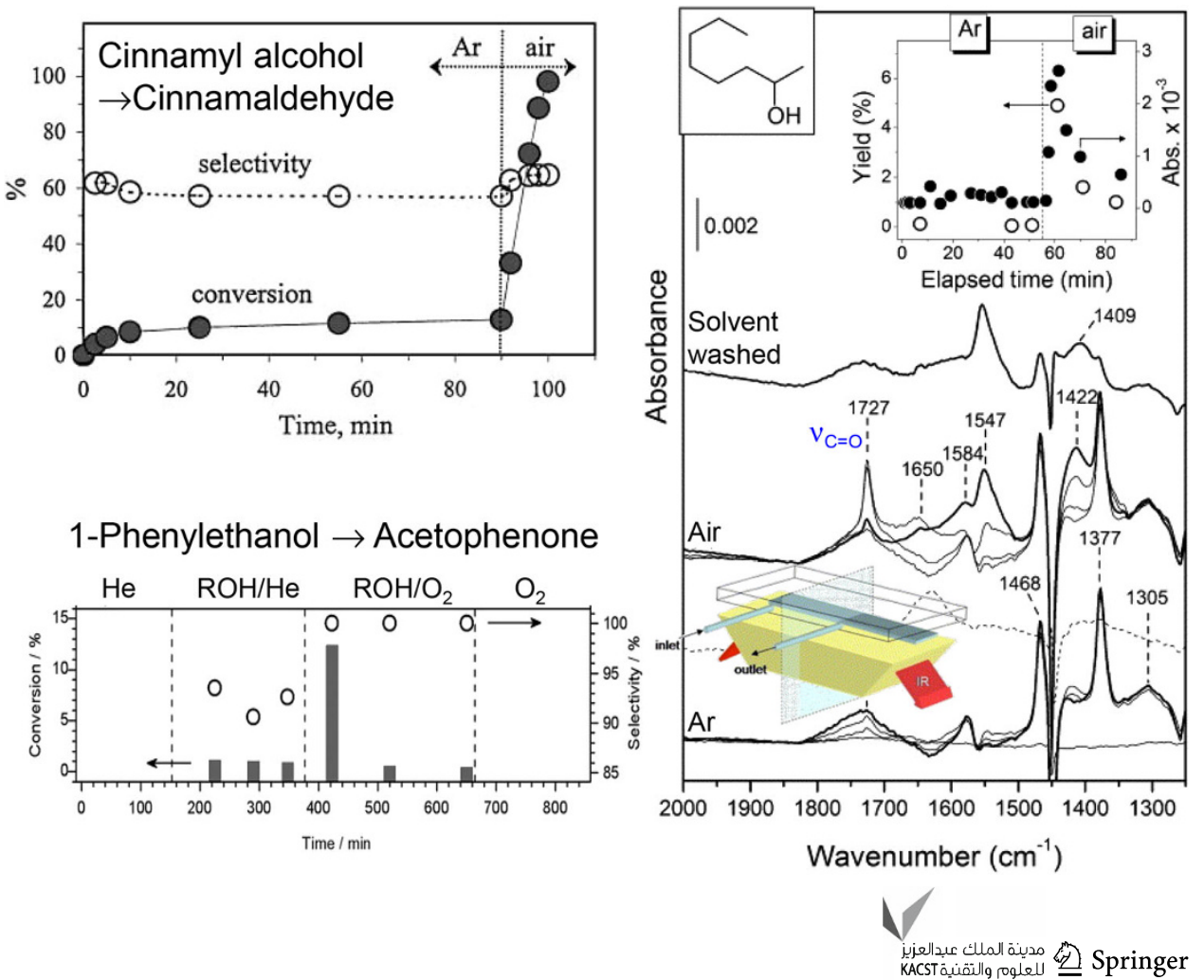
Fig. 13 (Top right)

Dependence of allylic alcohol selox rate upon surface $\mathrm{PdO}$; (top left) schematic of operando liquid phase reactor; (bottom left) evolution of Pd K-edge XAS of $\mathrm{Pd} / \mathrm{Al}_{2} \mathrm{O}_{3}$ catalyst during cinnamyl alcohol aerobic selox; (bottom right) temporal correspondence between Pd oxidation state and selox activity in cinnamyl alcohol selox. Adapted from references $[133,134]$ with permission from The Royal Society of Chemistry

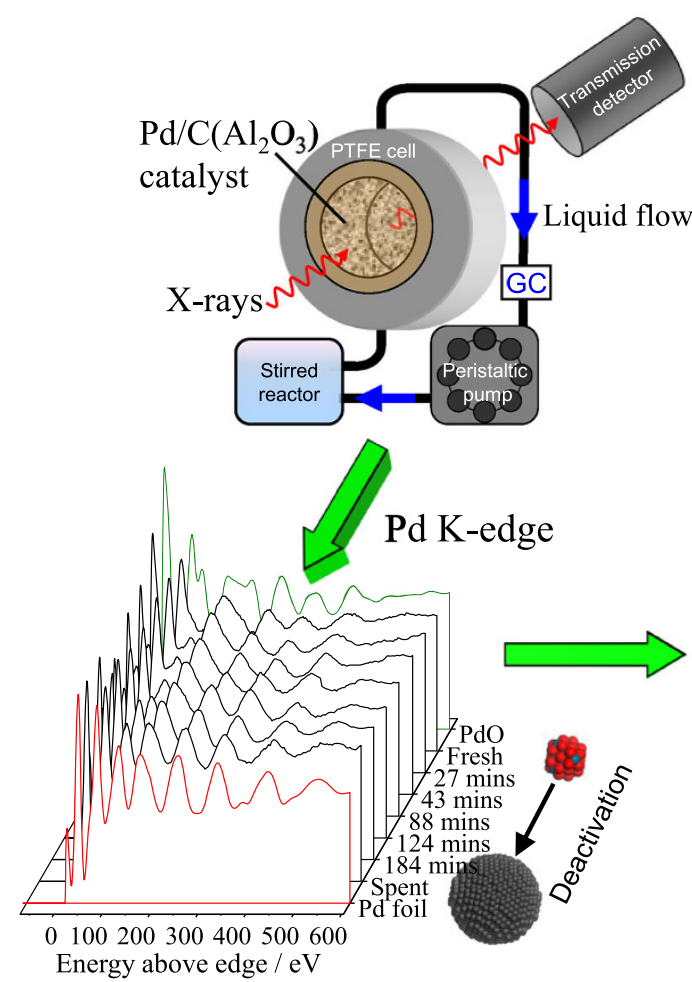

temperatures, palladium nanoparticles were partially oxidised, and unperturbed by exposure to sequential alcohol or oxygen pulses (Fig. 14). Crotonaldehyde formed immediately upon contact of crotyl alcohol with the oxide surface, but only desorbed upon oxygen co-adsorption. Higher reaction temperatures induced $\mathrm{PdO}$ reduction in response to crotyl alcohol exposure, mirroring that observed during liquid phase selox, however, this reduction could be fully reversed by subsequent oxygen exposure. Such reactantinduced restructuring was exhibited by all palladium nanoparticles, but the magnitude was inversely proportional to particle size [168]. These dynamic measurements decoupled the relative reactivity of palladium oxide from metal revealing that $\mathrm{PdO}$ favoured crotyl alcohol selox to crotonaldehyde and crotonic acid, whereas metallic palladium drove secondary decarbonylation to propene and $\mathrm{CO}$ in accordance with surface science predictions [143].

Recent ambient pressure XPS investigations of crotyl alcohol $/ \mathrm{O}_{2}$ gas mixtures over metallic and oxidised $\operatorname{Pd}(111)$ single crystal surfaces confirmed that only twodimensional $\mathrm{Pd}_{5} \mathrm{O}_{4}$ and three-dimensional $\mathrm{PdOx}$ surfaces were capable of crotonaldehyde production (Fig. 15) [169]. However, even under oxygen-rich conditions, on-stream reduction of the $\mathrm{Pd}_{5} \mathrm{O}_{4}$ monolayer oxide occurred $>70{ }^{\circ} \mathrm{C}$ accompanied by surface poisoning by hydrocarbon residues. In contrast, PdOx multilayers were capable of sustained catalytic turnover of crotyl alcohol to crotonaldehyde, conclusively proving surface palladium oxide as the active phase in allylic alcohol selox.
Establishing support effects

Anchoring Pd nanoparticles onto support structures offers an effective means to tune their physicochemical characteristics and prevent on-stream deactivation e.g. by sintering. Supports employing porous architectures, acid/base character and/or surface redox chemistry e.g. strong metal support interaction (SMSI), afford further opportunities to influence catalyst reactivity [170-173]. Mesoporous silicas are widely used to disperse metal nanoparticles [135, 136, 171, 174, 175]. The transition from low surface area, amorphous silica $\left(200 \mathrm{~m}^{2} \mathrm{~g}^{-1}\right)$ to two-dimensional noninterconnected pore channels (SBA-15) [73] and threedimensional interconnected porous frameworks (SBA-16, KIT-6) [73, 176, 177] improved the dispersion of Pd nanoparticles and hence degree of surface oxidation and thus activity in allylic alcohol selox (Fig. 16), but had little impact on the mass transport of small alcohols to/from the active site. [135, 136] The high thermal and chemical stability of such mesoporous silica $[178,179]$ makes such supports well-suited to commercialisation. Pd nanoparticles confined within such mesoporous silicas demonstrate good selectivity in crotyl and cinnamyl alcohol selox to their respective aldehydes ( $>70 \%$ ), and excellent TOFs of 7,000 and $5,000 \mathrm{~h}^{-1}$ for the respective alcohols. Similar activities are reported for secondary and tertiary allylic alcohols, highlighting the versatility of silica supported $\mathrm{Pd}$ nanoparticles [51, 135, 136, 180-182]. Incorporation of macropores into SBA-15 via dual hard/soft templating to 


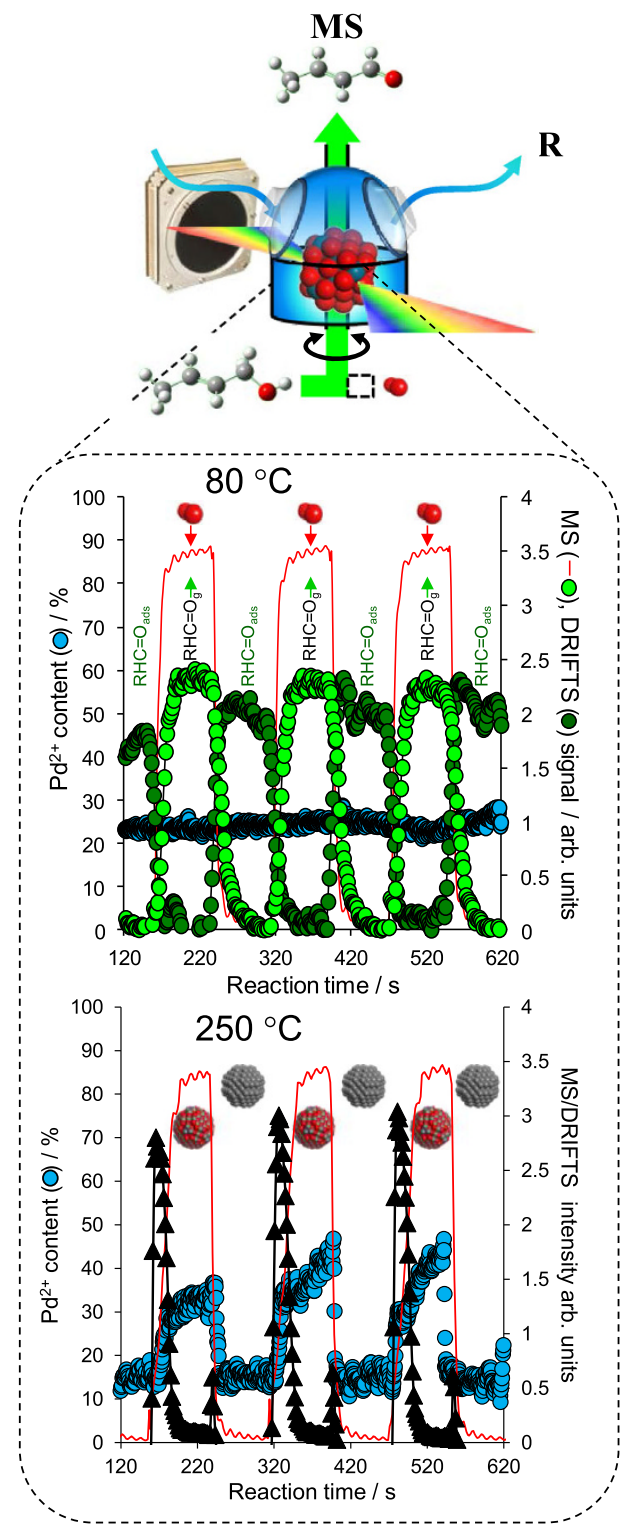

Fig. 14 (Left) Cartoon of operando DRIFTS/MS/XAS reaction cell and resulting temperature dependent behaviour of Pd oxidation state and associated reactivity towards crotyl alcohol oxidation over a Pd/ meso- $\mathrm{Al}_{2} \mathrm{O}_{3}$ catalyst-only selective oxidation over surface $\mathrm{PdO}$ occurs at $80{ }^{\circ} \mathrm{C}$, whereas crotonaldehyde decarbonylation and combustion dominate over $\mathrm{Pd}$ metal at $250{ }^{\circ} \mathrm{C}$; (top right) relationship

form a hierarchically ordered macroporous-mesoporous Pd/SBA-15 was recently shown to promote the catalytic selox of sterically challenging sesquiterpenoid substrates such as farnesol and phytol via (1) stabilising PdO nanoparticles and (2) dramatically improving in-pore diffusion and access to active sites [158].

The benefits of mesostructured supports are not limited to silica, with ultra-low loadings of palladium impregnated onto a surfactant-templated mesoporous alumina (350
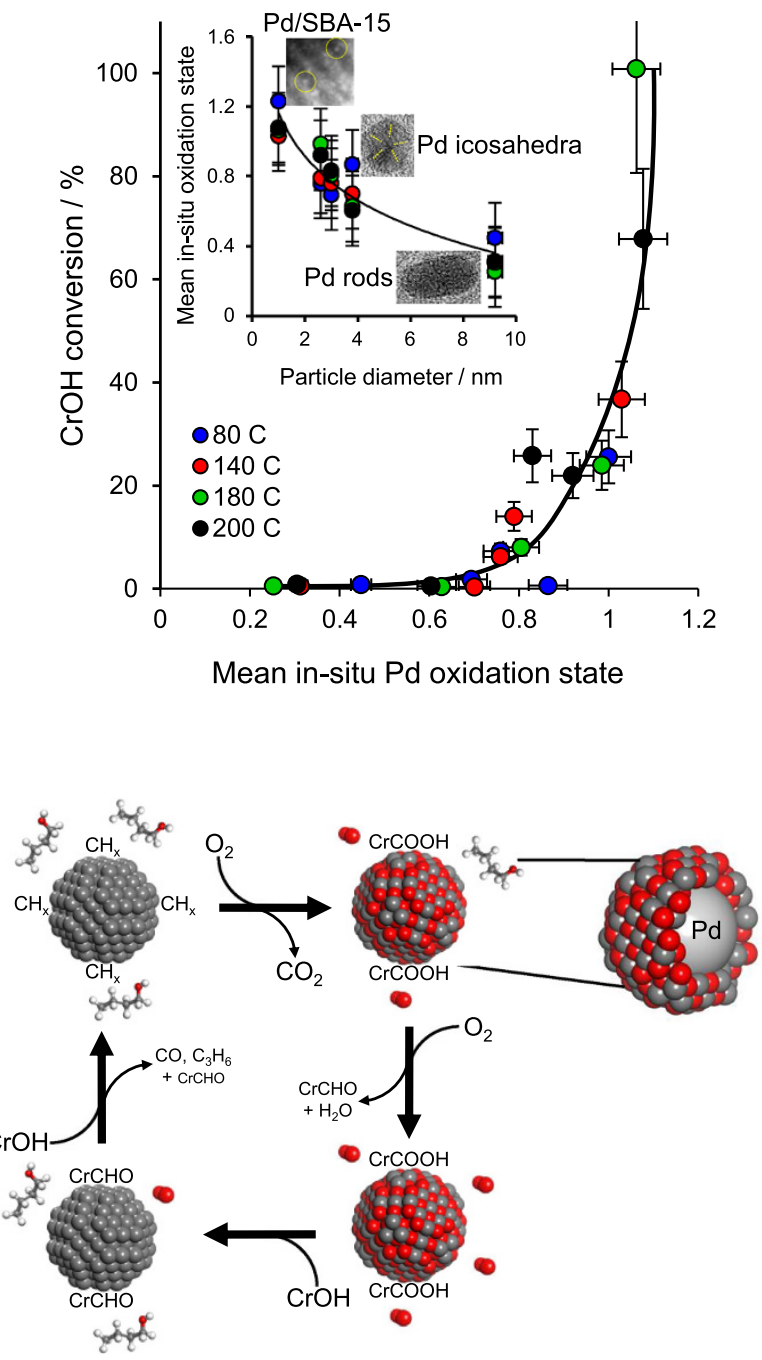

between Pd oxidation derived in situ and crotyl alcohol conversion; (bottom right) summary of reaction-induced redox processes in $\mathrm{Pd}-$ catalysed crotyl alcohol selox. Adapted with permission from references [166, 168]. Copyright 2011 and 2012 American Chemical Society

$\mathrm{m}^{2} \mathrm{~g}^{-1}$ ) generating atomically dispersed $\mathrm{Pd}^{2+}$ centres [137]. Such single-site catalysts were 10 times more active in crotonaldehyde and cinnamaldehyde production than comparable materials employing conventional $\left(100 \mathrm{~m}^{2} \mathrm{~g}^{-1}\right)$ $\gamma$-alumina, owing to the preferential genesis of higher concentrations of electron-deficient palladium [134, 137], due to either pinning at cation vacancies or metal $\rightarrow$ support charge transfer [183]. These $\mathrm{Pd} / \mathrm{meso}-\mathrm{Al}_{2} \mathrm{O}_{3}$ catalysts exhibited similar TOFs to their silica counterparts (7,080 and 


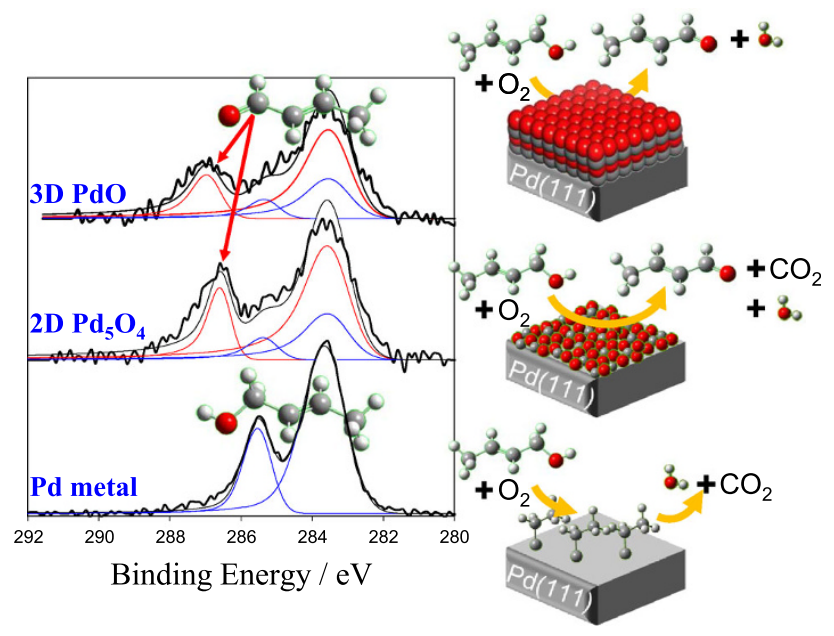

Fig. 15 (Left) $\mathrm{C} 1 \mathrm{~s}$ XP spectra of crotyl alcohol/ $\mathrm{O}_{2}$ gas mixture over metallic and oxidised Pd(111) surfaces; (right) differing reactivity of palladium metal and oxide surfaces. Adapted from reference [169]. Copyright 2012 American Chemical Society

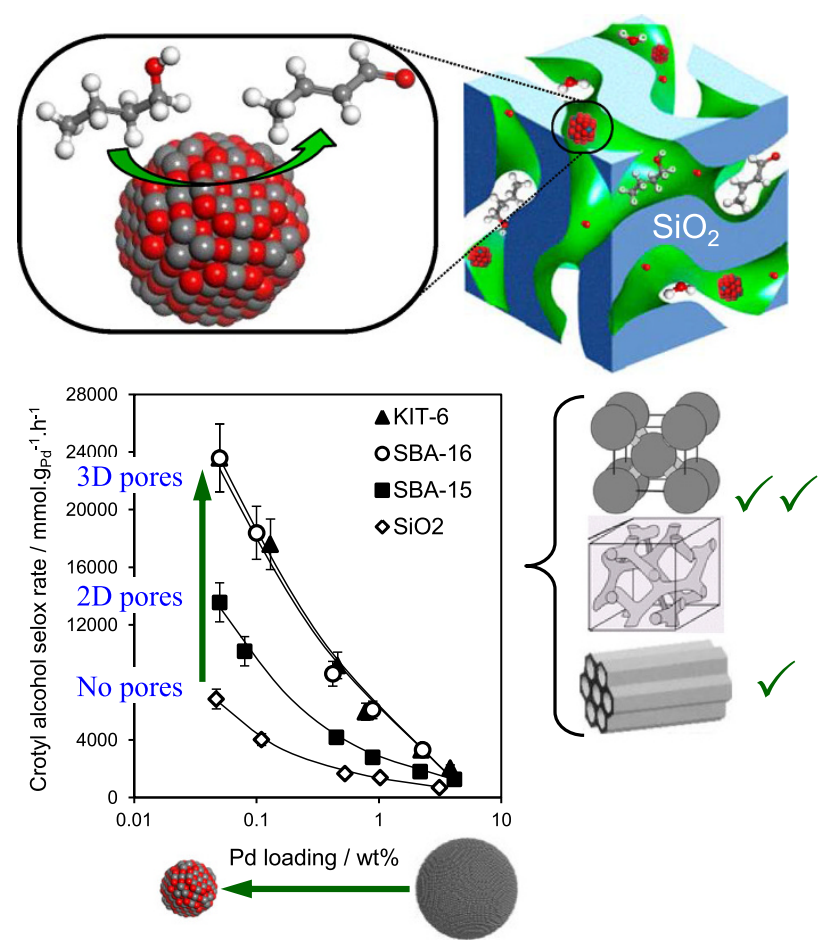

Fig. 16 Comparative activity of Pd nanoparticles dispersed over amorphous, 2D non-interconnected SBA-15 and 3D interconnected SBA-16 and KIT-6 mesoporous silicas in the selective aerobic oxidation of crotyl alcohol. Adapted from reference [135]. Copyright 2011 American Chemical Society

$4,400 \mathrm{~h}^{-1}$ for crotyl and cinnamyl alcohol selox, respectively) [137], consistent with a common active site and reaction mechanism (Fig. 17).

Mesoporous titania and ceria have also attracted interest as novel catalyst supports. The oxygen storage capacity of ceria-derived materials is of particular interest due to their facile $\mathrm{Ce}^{3+} \leftrightarrow \mathrm{Ce}^{4+}$ redox chemistry [173, 184-188]. Sacrificial reduction of the ceria supports by reactively formed hydrogen liberated during the oxidative dehydrogenation of alcohols could mitigate in situ reduction of oxidised palladium, and hence maintain selox activity and catalyst lifetime, with $\mathrm{Ce}^{4+}$ sites regenerated by dissociatively adsorbed gas phase oxygen $[187,189,190]$. Due to its high density, conventional nanocrystalline cerias possess meagre surface areas (typically $\sim 5 \mathrm{~m}^{2} \mathrm{~g}^{-1}$ ), hence $\mathrm{Pd} / \mathrm{CeO}_{2}$ typically exhibit poor selox behaviour due to their resultant low nanoparticle dispersions which favour (self-poisoning) metallic Pd [189, 191, 192].

\section{Bimetallic palladium selox catalysts}

Incorporation of a second metal into palladium catalysts can improve both alcohol selox stability and selectivity. Typical promoters such as $\mathrm{Ag}, \mathrm{Bi}, \mathrm{Pb}$ and $\mathrm{Sn}$ [157, 193196], enhance oxidation performance towards challenging substrates such as propylene glycol [197] as well as allylic and benzylic alcohols. Wenkin et al. [194] reported glucose oxidation to gluconates was increased by a factor of 20 over $\mathrm{Pd}-\mathrm{Bi} / \mathrm{C}$ catalysts $\left(\mathrm{Bi} / \mathrm{Pd}_{\mathrm{s}}=0.1\right)$ versus $\mathrm{Pd} / \mathrm{C}$ counterparts. In situ XAS and attenuated total reflection infrared spectroscopy (ATR-IR) suggested that Bi residing at the catalyst surface protects palladium from deactivation by either over-oxidation (a hypothesis since disproved [166, 167, 169]) or site-blocking by aromatic solvents [153]. Prati et al. [200] first reported significant rate enhancements and resistance to deactivation phenomena in the liquid phase selox of D-sorbitol to gluconic/gulonic acids upon addition of $\mathrm{Au}$ to $\mathrm{Pd} / \mathrm{C}$ and $\mathrm{Pt} / \mathrm{C}$ materials [198], subsequently extended to polyol and long chain aliphatic alcohols [199]. A strong synergy between $\mathrm{Pd}$ and $\mathrm{Au}$ centres was also demonstrated by Hutchings et al., wherein $\mathrm{Au}-\mathrm{Pd}$ alloy nanoparticles supported on titania exhibited increased reactivity towards a diverse range of primary, allylic and benzylic alkyl alcohols compared to monometallic palladium analogues. The versatility of $\mathrm{Au}-\mathrm{Pd}$ catalysts has also been shown in selox of saturated hydrocarbons [201], ethylene glycol [202], glycerol [203] and methanol [204], wherein high selectivity and resistance to on-stream deactivation is noted.

The effect of Au-Pd composition has been extensively studied for bimetallic nanoparticles stabilised by PVP surfactants [205]. An optimal Au:Pd composition of 1:3 was identified for $3 \mathrm{~nm}$ particles towards the aqueous phase aerobic selox of benzyl alcohol, 1-butanol, 2-butanol, 2-buten-1-ol and 1,4-butanediol; in each case the bimetallic catalysts were superior to palladium alone. Mertens et al. [206] examined similar systems utilising $1.9 \mathrm{~nm}$ nanoparticles, wherein an optimal Au content of around $80 \%$ was 

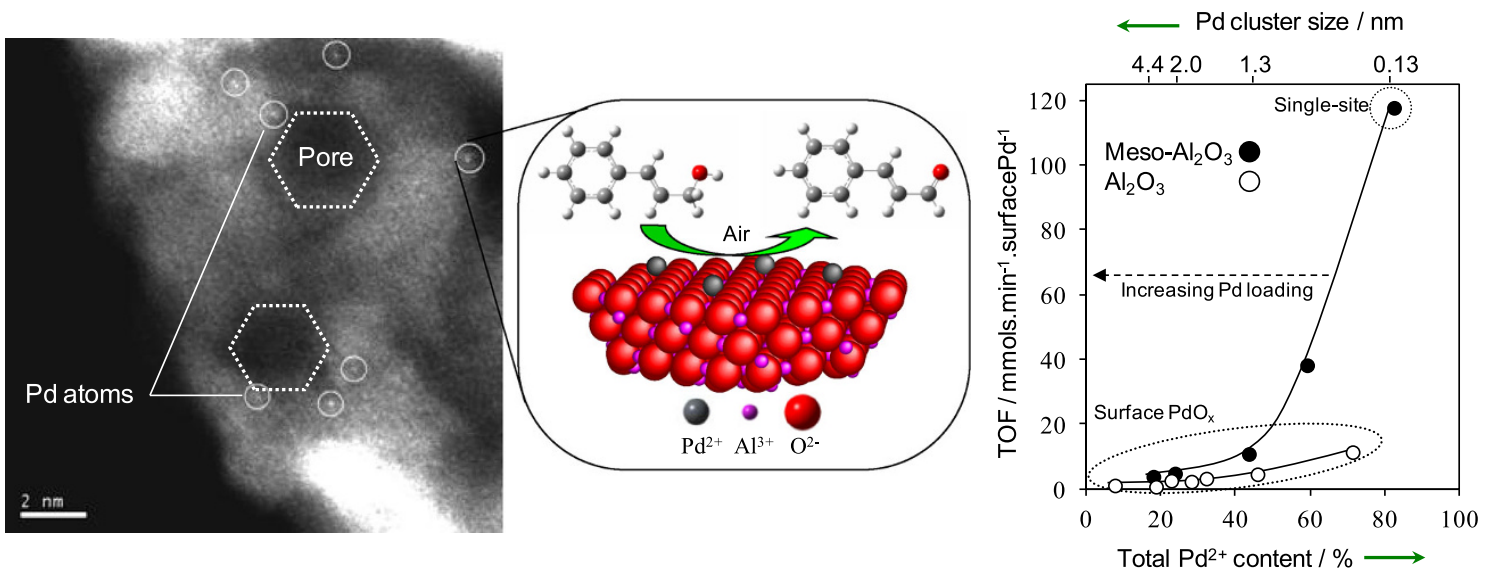

Fig. 17 (Left) HAADF-STEM image of atomically dispersed Pd atoms on a mesoporous $\mathrm{Al}_{2} \mathrm{O}_{3}$ support; and (right) associated relationship between $\mathrm{Pd}^{2+}$ content/dispersion and activity in crotyl

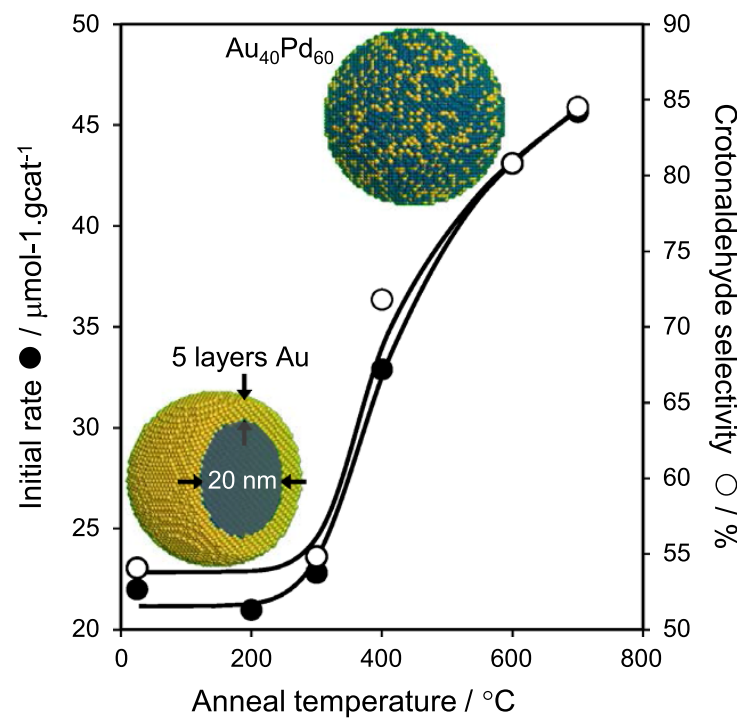

Fig. 18 Impact of thermally induced Au-Pd alloying of (left) titaniasupported Au shell-Pd core nanoparticles on crotyl alcohol aerobic selox adapted from reference [208], with permission from Elsevier; and (right) ultrathin gold overlayers on $\operatorname{Pd}(111)$ on crotonaldehyde

determined for benzyl alcohol selox. The synergic interaction between $\mathrm{Au}$ and Pd therefore appears interdependent on nanoparticle size. It is well-known that the catalytic activity of Au nanoparticles increases dramatically $<2 \mathrm{~nm}$ [207], hence it is interesting to systematically compare phase separated and alloyed catalysts. The author's group prepared titania-supported $\mathrm{Au}$ shell (5-layer)-Pd core $(20 \mathrm{~nm})$ bimetallic nanoparticles for the liquid phase selox of crotyl alcohol and systematically studied the evolution of their bulk and surface properties as a function of thermal processing by in situ XPS, DRIFTS, EXAFS, XRD and exsitu HRTEM. Limited Au/Pd alloying occurred below $300{ }^{\circ} \mathrm{C}$ in the absence of particle sintering [208]. Higher alcohol selox over Pd/alumina catalysts. Adapted with permission from reference [137]. Copyright Wiley-VCH Verlag GmbH \& Co. $\mathrm{KGaA}$

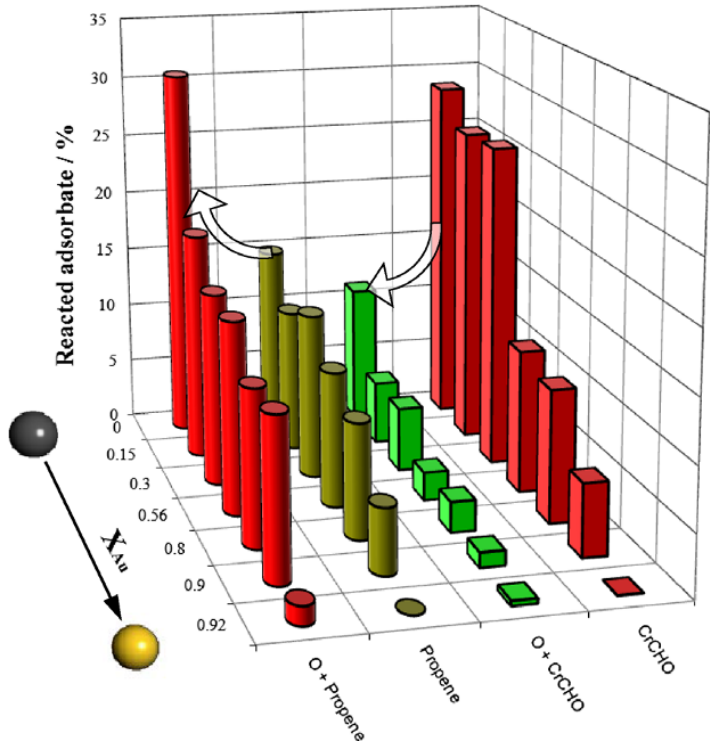

and propene decomposition with/without co-adsorbed oxygen, adapted from reference [160] with permission from the PCCP Owner Societies

temperatures induced bulk and surface alloying, with concomitant sintering and surface roughening. Migration of $\mathrm{Pd}$ atoms from the core to the surface dramatically enhanced activity and selectivity, with the most active and selective surface alloy containing 40 atom \% Au (Fig. 18). This discovery was rationalised in terms of complementary temperature-programmed mass spectometric studies of crotyl alcohol and reactively formed intermediates over $\mathrm{Au} /$ Pd(111) model single crystal catalysts which reveal that gold-palladium alloys promote desorption of the desired crotonaldehyde selox product while co-adsorbed oxygen adatoms actually suppress aldehyde combustion. In contrast, the combustion of propene, the undesired secondary 
product of crotonaldehyde decarbonylation, is enhanced by co-adsorbed oxygen [160].

Scott et al. prepared the inverse $\mathrm{Au}$ core-Pd shell nanoparticles and explored the catalytic cycle for alcohol selox to assess their associated stability [205, 209-212]. In situ $\mathrm{Pd}-\mathrm{K}$ and $\mathrm{Pd}-\mathrm{L}_{\mathrm{III}}$ edge XAS of a $\mathrm{Au}$ nanoparticle/ $\mathrm{Pd}(\mathrm{II})$ salt solution were undertaken to discriminate two possible reaction mechanisms. No evidence was found that crotyl alcohol oxidation was accompanied by $\mathrm{Pd}^{2+}$ reduction onto Au nanoparticles, resulting in the formation of a metallic Pd shell (with oxygen subsequently regenerating electron-deficient palladium), and therefore proposed $\beta-\mathrm{H}$ elimination as the favoured pathway. Scott and co-workers proposed that the $\mathrm{Au}$ core prevents the re-oxidation of surface $\mathrm{Pd}^{0}$ atoms; no $\mathrm{Pd}-\mathrm{O}$ and $\mathrm{Pd}-\mathrm{Cl}$ contributions were observed by EXAFS.

In summary, the selective oxidation of complex alcohol substrates can be accomplished through Pd-mediated heterogeneous catalysis with high turnover and product selectivity. Application of in situ and operando techniques, such as X-ray and IR spectroscopies, has elucidated the mechanism of alcohol oxidative dehydrogenation and competing aldehyde decarbonylation. Surface $\mathrm{PdO}$ has been identified as the active catalytic species, and deactivation the result of reduction to metallic palladium and concomitant self-poisoning by strongly bound $\mathrm{CO}$ and carbonaceous residues. Breakthroughs in analytical tools and synthetic approaches to engineering nanoporous supports and shape/size controlled nanoparticles have delivered significant progress towards improved atom and energy efficiency and catalyst stability, however, next generation palladium selox catalysts necessitate improved synthetic protocols to create higher densities of ultra-dispersed $\mathrm{Pd}^{2+}$ centres with superior resistance to on-stream reduction under atmospheric oxygen.

Acknowledgments A.F.L. thanks the EPSRC (EP/G007594/3) for financial support and a Leadership Fellowship, and acknowledges the invaluable contributions of Prof Karen Wilson (European Bioenergy Research Institute, Aston University).

Open Access This article is distributed under the terms of the Creative Commons Attribution License which permits any use, distribution, and reproduction in any medium, provided the original author(s) and the source are credited.

\section{References}

1. S. Kretzmann, http://priceofoil.org/2013/11/26/new-analysis-showsgrowing-fossil-reserves-shrinking-carbon-budget/

2. C.C. Authority, Reducing Australia's greenhouse gas emissions-targets and progress review draft report, commonwealth of Australia, 2013
3. C.C. Secretariat, The critical decade 2013 climate change science, risks and responses, commonwealth of Australia, 2013

4. I.E. Agency, prospect of limiting the global increase in temperature to $2{ }^{\circ} \mathrm{C}$ is getting bleaker, http://www.iea.org/ newsroomandevents/news/2011/may/name,19839,en.html

5. I.E. Agency, Redrawing the energy climate map, 2013

6. U.S.E.I. Administration, international energy outlook 2013, 2013

7. Armaroli N, Balzani V (2007) Angew Chem Int Ed 46:52-66

8. Azadi P, Inderwildi OR, Farnood R, King DA (2013) Renew Sustain Energy Rev 21:506-523

9. Demirbas A (2007) Energy Policy 35:4661-4670

10. McLaughlin DW (2011) Conserv Biol 25:1117-1120

11. Danielsen F, Beukema H, Burgess ND, Parish F, BrÜHl CA, Donald PF, Murdiyarso D, Phalan BEN, Reijnders L, Struebig M, Fitzherbert EB (2009) Conserv Biol 23:348-358

12. Achten WMJ, Verchot L, Franken YJ, Mathijs E, Singh VP, Aerts R, Muys B (2008) Biomass Bioenergy 32:1063-1084

13. Mata TM, Martins AA, Caetano NS (2010) Renew Sustain Energy Rev 14:217-232

14. BP, BP energy outlook 2030, 2011

15. Sheldon RA (2014) Green Chem 16:950-963

16. Pandey MP, Kim CS (2011) Chem Eng Technol 34:29-41

17. Knothe G (2010) Top Catal 53:714-720

18. Climent MJ, Corma A, Iborra S, Velty A (2004) J Catal 221:474-482

19. Constantino U, Marmottini F, Nocchetti M, Vivani R (1998) Eur J Inorg Chem 10:1439-1446

20. Narasimharao K, Lee A, Wilson K (2007) J Biobased Mater Bioenergy 1:19-30

21. Othman MR, Helwani Z, Martunus, Fernando WJN (2009) Appl Organomet Chem 23:335-346

22. Liu Y, Lotero E, Goodwin JG, Mo X (2007) Appl Catal A 33:138-148

23. Geuens J, Kremsner JM, Nebel BA, Schober S, Dommisse RA, Mittelbach M, Tavernier S, Kappe CO, Maes BUW (2007) Energy Fuels 22:643-645

24. Hu, Du, Tang Z, Min (2004) Ind Eng Chem Res 43:7928-7931

25. Knothe G (2005) Fuel Process Technol 86:1059-1070

26. Ma F, Hanna MA (1999) Bioresour Technol 70:1-15

27. Lotero E, Liu Y, Lopez DE, Suwannakarn K, Bruce DA, Goodwin JG (2005) Ind Eng Chem Res 44:5353-5363

28. Thomas JM (2012) Proc R Soc A Math Phys Eng Sci 468:1884-1903

29. Somorjai GA, Frei H, Park JY (2009) J Am Chem Soc 131:16589-16605

30. Luque R, Herrero-Davila L, Campelo JM, Clark JH, Hidalgo JM, Luna D, Marinas JM, Romero AA (2008) Energy Environ Sci 1:542-564

31. Luque R, Lovett JC, Datta B, Clancy J, Campelo JM, Romero AA (2010) Energy Environ Sci 3:1706-1721

32. Dacquin J-P, Lee AF, Wilson K (2010) Thermochemical conversion of biomass to liquid fuels and chemicals. The Royal Society of Chemistry, UK, pp 416-434

33. Wilson K, Lee AF (2012) Catal Sci Technol 2:884-897

34. Eze VC, Phan AN, Pirez C, Harvey AP, Lee AF, Wilson K (2013) Catal Sci Technol 3:2373-2379

35. Chen G-Q, Patel MK (2011) Chem Rev 112:2082-2099

36. Bozell JJ, Petersen GR (2010) Green Chem 12:539-554

37. Sheldon RA (2005) Green Chem 7:267-278

38. Sheldon RA, Arends I, Hanefeld U (2007) Green chemistry and catalysis. Wiley-VCH Verlag GmbH \& Co. KGaA, Weinheim

39. Mallat T, Baiker A (2004) Chem Rev 104:3037-3058

40. Lee AF (2014). In: Wilson K, Lee AF (eds) Heterogeneous catalysts for clean technology: spectroscopy, design, and 
monitoring chapt. 2. Wiley-VCH Verlag GmbH \& Co. KGaA, Weinheim, pp 11-33

41. Vinod CP, Wilson K, Lee AF (2011) J Chem Technol Biotechnol 86:161-171

42. Kobayashi S, Miyamura H, Akiyama R, Ishida T (2005) J Am Chem Soc 127:9251-9254

43. Kaizuka K, Lee KY, Miyamura H, Kobayashi S (2012) J Flow Chem 2:1

44. Ye XA, Johnson MD, Diao TN, Yates MH, Stahl SS (2010) Green Chem 12:1180-1186

45. Ayude A, Cechini J, Cassanello M, Martinez O, Haure P (2008) Chem Eng Sci 63:4969-4973

46. Tschan R, Wandeler R, Schneider MS, Schubert MM, Baiker A (2001) J Catal 204:219-229

47. Caravati M, Grunwaldt JD, Baiker A (2004) Catal Today 91-2:1-5

48. Grunwaldt JD, Caravati M, Baiker A (2006) J Phys Chem B 110:9916-9922

49. Burgener M, Tyszewski T, Ferri D, Mallat T, Baiker A (2006) Appl Catal A Gen 299:66-72

50. Hou ZS, Theyssen N, Leitner W (2007) Green Chem 9:127-132

51. Hou Z, Theyssen N, Brinkmann A, Klementiev KV, Grünert W, Bühl M, Schmidt W, Spliethoff B, Tesche B, Weidenthaler C (2008) J Catal 258:315-323

52. Beale AM, Jacques SDM, Weckhuysen BM (2010) Chem Soc Rev 39:4656-4672

53. Grunwaldt JD, Schroer CG (2010) Chem Soc Rev 39:4741-4753

54. Lee AF (2012) Aust J Chem 65:615-623

55. Gai PL, Sharma R, Ross FM (2008) MRS Bull 33:107-114

56. Jungjohann KL, Evans JE, Aguiar JA, Arslan I, Browning ND (2012) Microsc Microanal 18:621-627

57. Browning ND, Bonds MA, Campbell GH, Evans JE, Lagrange T, Jungjohann KL, Masiel DJ, Mckeown J, Mehraeen S, Reed BW, Santala M (2012) Curr Opin Solid State Mat Sci 16:23-30

58. Boyes ED, Ward MR, Lari L, Gai PL (2013) Ann Phys Berlin 525:423-429

59. Xiong Y, Cai H, Wiley BJ, Wang J, Kim MJ, Xia Y (2007) J Am Chem Soc 129:3665-3675

60. Zhang H, Jin M, Xiong Y, Lim B, Xia Y (2012) Acc Chem Res 46:1783-1794

61. Xia X, Choi S-I, Herron JA, Lu N, Scaranto J, Peng H-C, Wang J, Mavrikakis M, Kim MJ, Xia Y (2013) J Am Chem Soc 135:15706-15709

62. Astruc D, Lu F, Aranzaes JR (2005) Angew Chem Int Ed 44:7852-7872

63. Hermans I, Spier ES, Neuenschwander U, Turrà N, Baiker A (2009) Top Catal 52:1162-1174

64. Heyns K, Paulsen H (1957) Angew Chem 69:600-608

65. Liu XY, Madix RJ, Friend CM (2008) Chem Soc Rev $37: 2243-2261$

66. Dimitratos N, Lopez-Sanchez JA, Hutchings GJ (2012) Chem Sci 3:20-44

67. Besson M, Gallezot P (2000) Catal Today 57:127-141

68. Kluytmans J, Markusse A, Kuster B, Marin G, Schouten J (2000) Catal Today 57:143-155

69. Mallat T, Baiker A (1994) Catal Today 19:247-283

70. Narasimharao K, Brown DR, Lee AF, Newman AD, Siril PF, Tavener SJ, Wilson K (2007) J Catal 248:226-234

71. Suwannakarn K, Lotero E, Ngaosuwan K, Goodwin JG (2009) Ind Eng Chem Res 48:2810-2818

72. Kouzu M, Nakagaito A, Hidaka J-s (2011) Appl Catal A 405:36-44

73. Zhao D, Huo Q, Feng J, Chmelka BF, Stucky GD (1998) J Am Chem Soc 120:6024-6036

74. Mbaraka IK, Shanks BH (2005) J Catal 229:365-373
75. Melero JA, Bautista LF, Morales G, Iglesias J, Briones D (2008) Energy Fuels 23:539-547

76. Chen X-R, Ju Y-H, Mou C-Y (2007) J Phys Chem C 111:18731-18737

77. Mbaraka IK, Radu DR, Lin VSY, Shanks BH (2003) J Catal 219:329-336

78. Chen D, Li Z, Wan Y, Tu X, Shi Y, Chen Z, Shen W, Yu C, Tu B, Zhao D (2006) J Mater Chem 16:1511-1519

79. Cao L, Man T, Kruk M (2009) Chem Mater 21:1144-1153

80. Dacquin JP, Lee AF, Pirez C, Wilson K (2012) Chem Commun 48:212-214

81. Martin A, Morales G, Martinez F, van Grieken R, Cao L, Kruk M (2010) J Mater Chem 20:8026-8035

82. Pirez C, Caderon J-M, Dacquin J-P, Lee AF, Wilson K (2012) ACS Catal 2:1607-1614

83. Vinu A, Gokulakrishnan N, Balasubramanian VV, Alam S, Kapoor MP, Ariga K, Mori T (2008) Chem A Eur J 14:11529-11538

84. Melero JA, Iglesias J, Morales G (2009) Green Chem 11:1285-1308

85. Carrero A, Vicente G, Rodríguez R, Linares M, del Peso GL (2011) Catal Today 167:148-153

86. Ying JY, Mehnert CP, Wong MS (1999) Angew Chem Int Ed 38:56-77

87. Lu Y (2006) Angew Chem Int Ed 45:7664-7667

88. Garg S, Soni K, Kumaran GM, Bal R, Gora-Marek K, Gupta JK, Sharma LD, Dhar GM (2009) Catal Today 141:125-129

89. Gheorghiu S, Coppens M-O (2004) AIChE J 50:812-820

90. Zhang X, Zhang F, Chan K-Y (2004) Mater Lett 58:2872-2877

91. Sun J-H, Shan Z, Maschmeyer T, Coppens M-O (2003) Langmuir 19:8395-8402

92. Dacquin J-P, Dhainaut JRM, Duprez D, Royer SB, Lee AF, Wilson K (2009) J Am Chem Soc 131:12896-12897

93. Dhainaut J, Dacquin J-P, Lee AF, Wilson K (2010) Green Chem 12:296-303

94. Wilson K, Rénson A, Clark JH (1999) Catal Lett 61:51-55

95. Rác B, Hegyes P, Forgo P, Molnár Á (2006) Appl Catal A 299:193-201

96. Yang Q, Liu J, Yang J, Kapoor MP, Inagaki S, Li C (2004) J Catal 228:265-272

97. Yang Q, Kapoor MP, Shirokura N, Ohashi M, Inagaki S, Kondo JN, Domen K (2005) J Mater Chem 15:666-673

98. Morales G, Athens G, Chmelka BF, van Grieken R, Melero JA (2008) J Catal 254:205-217

99. Margolese D, Melero JA, Christiansen SC, Chmelka BF, Stucky GD (2000) Chem Mater 12:2448-2459

100. Díaz I, Márquez-Alvarez C, Mohino F, Pérez-Pariente JN, Sastre E (2000) J Catal 193:283-294

101. Dacquin J-P, Cross HE, Brown DR, Duren T, Williams JJ, Lee AF, Wilson K (2010) Green Chem 12:1383-1391

102. Schumacher C, Gonzalez J, Wright PA, Seaton NA (2005) J Phys Chem B 110:319-333

103. Pirez C, Wilson K, Lee AF (2014) Green Chem 16:197-202

104. Ono Y, Baba T (1997) Catal Today 38:321-337

105. Hattori H (1995) Chem Rev 95:537-558

106. Albuquerque MCG, Azevedo DCS, Cavalcante CL Jr, Santamaría-González J, Mérida-Robles JM, Moreno-Tost R, Rodríguez-Castellón E, Jiménez-López A, Maireles-Torres P (2009) J Mol Catal A: Chem 300:19-24

107. Peterson GR, Scarrah WP (1984) J Am Oil Chem Soc 61:1593-1597

108. Verziu M, Coman SM, Richards R, Parvulescu VI (2011) Catal Today 167:64-70

109. Granados ML, Alonso DM, Alba-Rubio AC, Mariscal R, Ojeda M, Brettes P (2009) Energy Fuels 23:2259-2263 
110. Di Serio M, Tesser R, Casale L, D'Angelo A, Trifuoggi M, Santacesaria E (2010) Top Catal 53:811-819

111. MacLeod CS, Harvey AP, Lee AF, Wilson K (2008) Chem Eng J 135:63-70

112. Montero J, Wilson K, Lee A (2010) Top Catal 53:737-745

113. Watkins RS, Lee AF, Wilson K (2004) Green Chem 6:335-340

114. Alonso DM, Mariscal R, Granados ML, Maireles-Torres $\mathrm{P}$ (2009) Catal Today 143:167-171

115. Verziu M, Cojocaru B, Hu J, Richards R, Ciuculescu C, Filip P, Parvulescu VI (2008) Green Chem 10:373-381

116. Zhu K, Hu J, Kübel C, Richards R (2006) Angew Chem Int Ed 45:7277-7281

117. Montero JM, Gai P, Wilson K, Lee AF (2009) Green Chem 11:265-268

118. Cantrell DG, Gillie LJ, Lee AF, Wilson K (2005) Appl Catal A 287:183-190

119. Di Serio M, Ledda M, Cozzolino M, Minutillo G, Tesser R, Santacesaria E (2006) Ind Eng Chem Res 45:3009-3014

120. Cavani F, Trifirò F, Vaccari A (1991) Catal Today 11:173-301

121. Barakos N, Pasias S, Papayannakos N (2008) Bioresour Technol 99:5037-5042

122. Fraile JM, García N, Mayoral JA, Pires E, Roldán L (2009) Appl Catal A 364:87-94

123. Cross HE, Brown DR (2010) Catal Commun 12:243-245

124. Woodford JJ, Dacquin J-P, Wilson K, Lee AF (2012) Energy Environ Sci 5:6145-6150

125. D Highley, A Bloodworth, R Bate Dolomite-mineral planning factsheet, British Geological Survey, 2006

126. Sutton D, Kelleher B, Ross JRH (2001) Fuel Process Technol 73:155-173

127. Wilson K, Hardacre C, Lee AF, Montero JM, Shellard L (2008) Green Chem 10:654-659

128. Ilgen O (2011) Fuel Process Technol 92:452-455

129. Scharff Y, Asteris D, Fédou S (2013) OCL 20:D502

130. Choi K-M, Akita T, Mizugaki T, Ebitani K, Kaneda K (2003) New J Chem 27:324-328

131. Chen J, Zhang Q, Wang Y, Wan H (2008) Adv Synth Catal 350:453-464

132. Li F, Zhang Q, Wang Y (2008) Appl Catal A 334:217-226

133. Lee AF, Wilson K (2004) Green Chem 6:37

134. Lee AF, Hackett SF, Hargreaves JS, Wilson K (2006) Green Chem 8:549-555

135. Parlett CMA, Bruce DW, Hondow NS, Lee AF, Wilson K (2011) ACS Catal 1:636-640

136. Parlett CMA, Bruce DW, Hondow NS, Newton MA, Lee AF, Wilson K (2013) Chem Cat Chem 5:939-950

137. Hackett SF, Brydson RM, Gass MH, Harvey I, Newman AD, Wilson K, Lee AF (2007) Angew Chem 119:8747-8750

138. Baeza J, Calvo L, Gilarranz M, Mohedano A, Casas J, Rodriguez J (2012) J Catal 293:85-93

139. Wang X, Yang H, Feng B, Hou Z, Hu Y, Qiao Y, Li H, Zhao X (2009) Catal Lett 132:34-40

140. Yudha S, Dhital RN, Sakurai H (2011) Tetrahedron Lett 52:2633-2637

141. Dun R, Wang X, Tan M, Huang Z, Huang X, Ding W, Lu X (2013) ACS Catal 3:3063-3066

142. Weldon MK, Friend CM (1996) Chem Rev 96:1391-1412

143. Lee AF, Chang Z, Ellis P, Hackett SF, Wilson K (2007) J Phys Chem C 111:18844-18847

144. Naughton J, Pratt A, Woffinden CW, Eames C, Tear SP, Thompson SM, Lee AF, Wilson K (2011) J Phys Chem C 115:25290-25297

145. Davis JL, Barteau MA (1987) Surf Sci 187:387-406

146. Davis JL, Barteau MA (1990) Surf Sci 235:235-248

147. Zaera F (2003) Catal Lett 91:1-10
148. Keresszegi C, Burgi T, Mallat T, Baiker A (2002) J Catal 211:244-251

149. Lee AF (2001) Abstr Pap Am Chem Soc 221:U335-U336

150. Grunwaldt J-D, Keresszegi C, Mallat T, Baiker A (2003) J Catal 213:291-295

151. Keresszegi C, Grunwaldt J-D, Mallat T, Baiker A (2004) J Catal 222:268-280

152. Grunwaldt J-D, Caravati M, Baiker A (2006) J Phys Chem B 110:25586-25589

153. Mondelli C, Ferri D, Grunwaldt J-D, Krumeich F, Mangold S, Psaro R, Baiker A (2007) J Catal 252:77-87

154. Keresszegi C, Ferri D, Mallat T, Baiker A (2005) J Catal 234:64-75

155. Caravati M, Meier DM, Grunwaldt J-D, Baiker A (2006) J Catal 240:126-136

156. Mallat T, Baiker A (1995) Catal Today 24:143-150

157. Mallat T, Bodnar Z, Hug P, Baiker A (1995) J Catal 153:131-143

158. Parlett CMA, Keshwalla P, Wainwright SG, Bruce DW, Hondow NS, Wilson K, Lee AF (2013) ACS Catal 3:2122-2129

159. Parlett CMA, Durndell LJ, Wilson K, Bruce DW, Hondow NS, Lee AF (2014) Catal Commun 44:40-45

160. Naughton J, Lee AF, Thompson S, Vinod CP, Wilson K (2010) Phys Chem Chem Phys 12:2670-2678

161. Ping EW, Pierson J, Wallace R, Miller JT, Fuller TF, Jones CW (2011) Appl Catal A 396:85-90

162. Newton MA, Jyoti B, Dent AJ, Fiddy SG, Evans J (2004) Chem Commun 2004:2382-2383

163. Ferri D, Baiker A (2009) Top Catal 52:1323-1333

164. Newton MA (2009) Top Catal 52:1410-1424

165. Newton MA, Dent AJ, Fiddy SG, Jyoti B, Evans J (2007) Catal Today 126:64-72

166. Lee AF, Ellis CV, Naughton JN, Newton MA, Parlett CM, Wilson K (2011) J Am Chem Soc 133:5724-5727

167. Parlett CMA, Gaskell CV, Naughton JN, Newton MA, Wilson K, Lee AF (2013) Catal Today 205:76-85

168. Gaskell CV, Parlett CMA, Newton MA, Wilson K, Lee AF (2012) ACS Catal 2:2242-2246

169. Lee AF, Naughton JN, Liu Z, Wilson K (2012) ACS Catal 2:2235-2241

170. Tauster S (1987) Acc Chem Res 20:389-394

171. Ghedini E, Menegazzo F, Signoretto M, Manzoli M, Pinna F, Strukul G (2010) J Catal 273:266-273

172. Hicks RF, Qi H, Young ML, Lee RG (1990) J Catal 122:295-306

173. Beckers J, Rothenberg G (2010) Green Chem 12:939-948

174. Inumaru K, Nakamura K, Ooyachi K, Mizutani K, Akihara S, Yamanaka S (2010) J Porous Mater 18:455-463

175. Liu Y-M, Cao Y, Yi N, Feng W-L, Dai W-L, Yan S-R, He H-Y, Fan K-N (2004) J Catal 224:417-428

176. Kim T-W, Kleitz F, Paul B, Ryoo R (2005) J Am Chem Soc 127:7601-7610

177. Zhao D, Feng J, Huo Q, Melosh N, Fredrickson GH, Chmelka BF, Stucky GD (1998) Science 279:548-552

178. Sneh O, George SM (1995) J Phys Chem 99:4639-4647

179. Kim JM, Kwak JH, Jun S, Ryoo R (1995) J Phys Chem 99:16742-16747

180. Kaneda K, Fujii M, Morioka K (1996) J Org Chem 61:4502-4503

181. Polshettiwar V, Varma RS (2009) Org Biomol Chem 7:37-40

182. Peterson KP, Larock RC (1998) J Org Chem 63:3185-3189

183. Behafarid F, Ono LK, Mostafa S, Croy JR, Shafai G, Hong S, Rahman TS, Bare SR, Cuenya BR (2012) Phys Chem Chem Phys 14:11766-11779

184. Yuan Q, Duan HH, Li LL, Sun LD, Zhang YW, Yan CH (2009) J Colloid Interface Sci 335:151-167 
185. Lykhach Y, Staudt T, Lorenz MPA, Streber R, Bayer A, Steinrück H-P, Libuda J (2010) Chem Phys Chem 11:1496-1504

186. Tana, Zhang M, Li J, Li H, Li Y, Shen W (2009) Catal Today 148:179-183

187. Bensalem A, Bozon-Verduraz F, Perrichon V (1995) J Chem Soc Faraday Trans 91:2185-2189

188. Harrison B, Diwell A, Hallett C (1988) Plat Met Rev 32:73-83

189. Zhu Y, Zhang S, Shan J-j, Nguyen L, Zhan S, Gu X, Tao F (2013) ACS Catal 3:2627-2639

190. Maillet T, Madier Y, Taha R, Barbier J Jr, Duprez D (1997) Stud Surf Sci Catal 112:267-275

191. Oh S-H, Hoflund GB (2006) J Phys Chem A 110:7609-7613

192. Badri A, Binet C, Lavalley J-C (1996) J Chem Soc Faraday Trans 92:1603-1608

193. Lee AF, Gee JJ, Theyers HJ (2000) Green Chem 2:279-282

194. Wenkin M, Ruiz P, Delmon B, Devillers M (2002) J Mol Catal A: Chem 180:141-159

195. Alardin F, Delmon B, Ruiz P, Devillers M (2000) Catal Today 61:255-262

196. Keresszegi C (2004) J Catal 225:138-146

197. Pinxt H, Kuster B, Marin G (2000) Appl Catal A 191:45-54

198. Dimitratos N, Porta F, Prati L, Villa A (2005) Catal Lett 99:181-185

199. Prati L, Villa A, Campione C, Spontoni P (2007) Top Catal 44:319-324
200. Enache DI, Edwards JK, Landon P, Solsona-Espriu B, Carley AF, Herzing AA, Watanabe M, Kiely CJ, Knight DW, Hutchings GJ (2006) Science 311:362-365

201. Long J, Liu H, Wu S, Liao S, Li Y (2013) ACS Catal 3:647-654

202. Griffin MB, Rodriguez AA, Montemore MM, Monnier JR, Williams CT, Medlin JW (2013) J Catal 307:111-120

203. Liu Z, Xu J, Zhang H, Zhao Y, Yu B, Chen S, Li Y, Hao L, Green Chem 2013

204. Wang R, Wu Z, Chen C, Qin Z, Zhu H, Wang G, Wang H, Wu C, Dong W, Fan W (2013) Chem Commun 49:8250-8252

205. Hou W, Dehm NA, Scott RW (2008) J Catal 253:22-27

206. Mertens P, Corthals S, Ye X, Poelman H, Jacobs P, Sels B, Vankelecom I, De Vos D (2009) J Mol Catal A: Chem 313:14-21

207. Hutchings GJ (2005) Catal Today 100:55-61

208. Lee AF, Ellis CV, Wilson K, Hondow NS (2010) Catal Today 157:243-249

209. Scott RW, Wilson OM, Oh S-K, Kenik EA, Crooks RM (2004) J Am Chem Soc 126:15583-15591

210. Scott RW, Sivadinarayana C, Wilson OM, Yan Z, Goodman DW, Crooks RM (2005) J Am Chem Soc 127:1380-1381

211. Dash P, Bond T, Fowler C, Hou W, Coombs N, Scott RWJ (2009) J Phys Chem C 113:12719-12730

212. Maclennan A, Banerjee A, Hu Y, Miller JT, Scott RWJ (2013) ACS Catal 3:1411-1419 